\title{
Approximating Common Fixed Points of Bregman Weakly Relatively Nonexpansive Mappings in Banach Spaces
}

\author{
Chin-Tzong Pang ${ }^{1}$ and Eskandar Naraghirad ${ }^{2,3}$ \\ ${ }^{1}$ Department of Information Management, Yuan Ze University, Chung-Li 32003, Taiwan \\ ${ }^{2}$ Department of Mathematics, Yasouj University, Yasouj 75918, Iran \\ ${ }^{3}$ Department of Applied Mathematics, National Sun Yat-Sen University, Kaohsiung 804, Taiwan
}

Correspondence should be addressed to Eskandar Naraghirad; eskandarrad@gmail.com

Received 8 September 2013; Accepted 1 December 2013; Published 3 February 2014

Academic Editor: Yakov Alber

Copyright (C) 2014 C.-T. Pang and E. Naraghirad. This is an open access article distributed under the Creative Commons Attribution License, which permits unrestricted use, distribution, and reproduction in any medium, provided the original work is properly cited.

Using Bregman functions, we introduce a new hybrid iterative scheme for finding common fixed points of an infinite family of Bregman weakly relatively nonexpansive mappings in Banach spaces. We prove a strong convergence theorem for the sequence produced by the method. No closedness assumption is imposed on a mapping $T: C \rightarrow C$, where $C$ is a closed and convex subset of a reflexive Banach space $E$. Furthermore, we apply our method to solve a system of equilibrium problems in reflexive Banach spaces. Some application of our results to the problem of finding a minimizer of a continuously Fréchet differentiable and convex function in a Banach space is presented. Our results improve and generalize many known results in the current literature.

\section{Introduction}

Throughout this paper, we denote the set of real numbers and the set of positive integers by $\mathbb{R}$ and $\mathbb{N}$, respectively. Let $E$ be a Banach space with the norm $\|\cdot\|$ and the dual space $E^{*}$. For any $x \in E$, we denote the value of $x^{*} \in E^{*}$ at $x$ by $\left\langle x, x^{*}\right\rangle$. Let $\left\{x_{n}\right\}_{n \in \mathbb{N}}$ be a sequence in $E$; we denote the strong convergence of $\left\{x_{n}\right\}_{n \in \mathbb{N}}$ to $x \in E$ as $n \rightarrow \infty$ by $x_{n} \rightarrow x$ and the weak convergence by $x_{n} \rightarrow x$. The modulus $\delta$ of convexity of $E$ is denoted by

$$
\delta(\epsilon)=\inf \left\{1-\frac{\|x+y\|}{2}:\|x\| \leq 1,\|y\| \leq 1,\|x-y\| \geq \epsilon\right\}
$$

for every $\epsilon$ with $0 \leq \epsilon \leq 2$. A Banach space $E$ is said to be uniformly convex if $\delta(\epsilon)>0$ for every $\epsilon>0$. Let $S_{E}=\{x \in E$ : $\|x\|=1\}$. The norm of $E$ is said to be Gâteaux differentiable if, for each $x, y \in S_{E}$, the limit

$$
\lim _{t \rightarrow 0} \frac{\|x+t y\|-\|x\|}{t}
$$

exists. In this case, $E$ is called smooth. If the limit (2) is attained uniformly for all $x, y \in S_{E}$, then $E$ is called uniformly smooth. The Banach space $E$ is said to be strictly convex if $\|(x+y) / 2\|<$ 1 whenever $x, y \in S_{E}$ and $x \neq y$. It is well known that $E$ is uniformly convex if and only if $E^{*}$ is uniformly smooth. It is also known that if $E$ is reflexive, then $E$ is strictly convex if and only if $E^{*}$ is smooth; for more details, see [1-3].

Let $C$ be a nonempty subset of $E$. Let $T: C \rightarrow E$ be a mapping. We denote the set of fixed points of $T$ by $F(T)$; that is, $F(T)=\{x \in C: T x=x\}$. A mapping $T: C \rightarrow E$ is said to be nonexpansive if $\|T x-T y\| \leq\|x-y\|$ for all $x, y \in C$. A mapping $T: C \rightarrow E$ is said to be quasinonexpansive if $F(T) \neq \emptyset$ and $\|T x-y\| \leq\|x-y\|$ for all $x \in C$ and $y \in F(T)$. The mapping $T$ is called closed, if for any sequence $\left\{x_{n}\right\}_{n \in \mathbb{N}} \subset C$ with $\lim _{n \rightarrow \infty} x_{n}=x_{0}$ and $\lim _{n \rightarrow \infty} T x_{n}=y_{0}$, then we have $T x_{0}=y_{0}$. Let $T: C \rightarrow C$ be a nonexpansive mapping. Recall that the Mann-type [4] iteration is given by the following formula:

$$
x_{n+1}=\gamma_{n} T x_{n}+\left(1-\gamma_{n}\right) x_{n}, \quad x_{1} \in C
$$


Here, $\left\{\gamma_{n}\right\}_{n \in \mathbb{N}}$ is a sequence of real numbers in $[0,1]$ satisfying some appropriate conditions. A more general iteration scheme is the Halpern [5] iteration given by

$$
\begin{aligned}
& u \in C, \quad x_{1} \in C \text { chosen arbitrarily, } \\
& y_{n}=\left(1-\beta_{n}\right) x_{n}+\beta_{n} T x_{n}, \\
& x_{n+1}=\alpha_{n} u+\left(1-\alpha_{n}\right) y_{n},
\end{aligned}
$$

where the sequences $\left\{\beta_{n}\right\}_{n \in \mathbb{N}}$ and $\left\{\alpha_{n}\right\}_{n \in \mathbb{N}}$ satisfy some appropriate conditions. Numerous results have been proved on Mann's and Halpern's iterations for nonexpansive mappings in Hilbert and Banach spaces (see, e.g., [6-11]).

Let $E$ be a smooth, strictly convex, and reflexive Banach space and let $J$ be the normalized duality mapping of $E$. Let $C$ be a nonempty, closed, and convex subset of $E$. The generalized projection $\Pi_{C}$ from $E$ onto $C$ [12] is defined and denoted by

$$
\Pi_{C}(x)=\underset{y \in C}{\arg \min } \phi(y, x),
$$

where $\phi(x, y)=\|x\|^{2}-2\langle x, J y\rangle+\|y\|^{2}$. Let $C$ be a nonempty, closed, and convex subset of smooth Banach space $E$ and let $T$ be a mapping from $C$ into itself. A point $p \in C$ is said to be an asymptotic fixed point [13] of $T$ if there exists a sequence $\left\{x_{n}\right\}_{n \in \mathbb{N}}$ in $C$ which converges weakly to $p$ and $\lim _{n \rightarrow \infty} \| x_{n}-$ $T x_{n} \|=0$. We denote the set of all asymptotic fixed points of $T$ by $\widehat{F}(T)$. A point $p \in C$ is called a strong asymptotic fixed point of $T$ if there exists a sequence $\left\{x_{n}\right\}_{n \in \mathbb{N}}$ in $C$ which converges strongly to $p$ and $\lim _{n \rightarrow \infty}\left\|x_{n}-T x_{n}\right\|=0$. We denote the set of all strong asymptotic fixed points of $T$ by $\widetilde{F}(T)$.

Following Matsushita and Takahashi [14], a mapping $T$ : $C \rightarrow C$ is said to be relatively nonexpansive if the following conditions are satisfied:

(1) $F(T)$ is nonempty;

(2) $\phi(u, T x) \leq \phi(u, x), \forall u \in F(T), x \in C$;

(3) $\widehat{F}(T)=F(T)$.

The mapping $T$ is called relatively weak quasinonexpansive $[15,16]$ if the following conditions are satisfied:

(1) $F(T)$ is nonempty;

(2) $\phi(u, T x) \leq \phi(u, x), \forall u \in F(T), x \in C$.

In 2005, Matsushita and Takahashi [14] proved the following strong convergence theorem for relatively nonexpansive mappings in a Banach space.

Theorem 1. Let $E$ be a uniformly convex and uniformly smooth Banach space, let $C$ be a nonempty, closed, and convex subset of $E$, let $T$ be a relatively nonexpansive mapping from $C$ into itself, and let $\left\{\alpha_{n}\right\}_{n \in \mathbb{N}}$ be a sequence of real numbers such that $0 \leq \alpha_{n}<1$ and $\lim \sup _{n \rightarrow \infty} \alpha_{n}<1$. Suppose that $\left\{x_{n}\right\}_{n \in \mathbb{N} \cup\{0\}}$ is given by

$$
\begin{aligned}
& x_{0}=x \in C, \\
& y_{n}=J^{-1}\left(\alpha_{n} J x_{n}+\left(1-\alpha_{n}\right) J T x_{n}\right), \\
& H_{n}=\left\{z \in C_{n}: \phi\left(z, y_{n}\right) \leq \phi\left(z, x_{n}\right)\right\}, \\
& W_{n}=\left\{z \in C:\left\langle x_{n}-z, J x-J x_{n}\right\rangle \geq 0\right\}, \\
& x_{n+1}=\Pi_{H_{n}} \cap W_{n} x .
\end{aligned}
$$

Then $\left\{x_{n}\right\}_{n \in \mathbb{N}}$ converges strongly to $\Pi_{F(T)} x$.

In 2010, Plubtieng and Ungchittrakool [17] proved the following strong convergence theorem for relatively nonexpansive mappings in a Banach space.

Theorem 2. Let $E$ be a uniformly convex and uniformly smooth Banach space and let $\widehat{C}$ and $C$ be two nonempty, closed, and convex subsets of E such that $C \subset \widehat{C}$. Let $\left\{T_{n}\right\}_{n \in \mathbb{N}}$ be a sequence of relatively nonexpansive mappings from $C$ into $E$ such that $\cap_{n=1}^{\infty} F\left(T_{n}\right)$ is nonempty and let $\left\{x_{n}\right\}_{n \in \mathbb{N}}$ be a sequence defined as follows:

$$
\begin{aligned}
& x_{0} \in \widehat{C}, \\
& C_{1}=C, \\
& x_{1}=\prod_{C_{1}} x_{0}, \\
& y_{n}=J^{-1}\left(\alpha_{n} J x_{n}+\left(1-\alpha_{n}\right) J T_{n} x_{n}\right), \\
& C_{n+1}=\left\{z \in C_{n}: \phi\left(z, y_{n}\right) \leq \phi\left(z, x_{n}\right)\right\}, \\
& x_{n+1}=\prod_{C_{n}} x_{0}, \quad n \in \mathbb{N},
\end{aligned}
$$

where $\left\{\alpha_{n}\right\}_{n \in \mathbb{N}} \subset[0,1]$ satisfies either

(a) $0 \leq \alpha_{n}<1$ for all $n \in \mathbb{N}$ and $\lim \sup _{n \rightarrow \infty} \alpha_{n}<1$ or

(b) $\lim \inf _{n \rightarrow \infty} \alpha_{n}\left(1-\alpha_{n}\right)>0$.

Suppose that for any bounded subset $B$ of $C$, there exists an increasing, continuous, and convex function $h_{B}:[0,+\infty) \rightarrow$ $[0,+\infty)$ such that $h_{B}(0)=0$, and $\lim _{k, l \rightarrow \infty} \sup \left\{h_{B}\left(\| T_{k} z-\right.\right.$ $\left.\left.T_{l} z \|\right): z \in B\right\}=0$. Let $T$ be a mapping from $C$ into $E$ defined by $T x=\lim _{n \rightarrow \infty} T_{n} x$ for all $x \in C$ and suppose that $F(T)=\cap_{n=1}^{\infty} F\left(T_{n}\right)=\cap_{n=1}^{\infty} \widetilde{F}\left(T_{n}\right)=\widetilde{F}(T)$. Then $\left\{x_{n}\right\}_{n \in \mathbb{N}}$, $\left\{T_{n} x_{n}\right\}_{n \in \mathbb{N}}$, and $\left\{y_{n}\right\}_{n \in \mathbb{N}}$ converge strongly to $\Pi_{F(T)} x_{0}$.

In 2010, Cai and $\mathrm{Hu}$ [15] proved the following strong convergence theorem for a finite family of closed relatively weak quasinonexpansive mappings in a Banach space.

Theorem 3. Let $C$ be a nonempty, closed, and let convex subset of uniformly convex and uniformly smooth Banach space $E$ and let $\left\{T_{1}, T_{2}, \ldots, T_{N}\right\}$ be a finite family of closed relatively weak quasinonexpansive mappings from $C$ into itself with $F:=$ $\cap_{i=1}^{N} F\left(T_{i}\right) \neq \varnothing$. Assume that $T_{i}$ is uniformly continuous for all 
$i \in\{1,2, \ldots, N\}$. Let $\left\{x_{n}\right\}_{n \in \mathbb{N}}$ be a sequence generated by the following algorithm

$$
\begin{aligned}
& x_{0}=x \in C \text { chosen arbitrarily, } \\
& C_{1}=C, \\
& x_{1}=\Pi_{C_{1}} x_{0}, \\
& z_{n}=J^{-1}\left[\beta_{n} J x_{n-1}+\left(1-\beta_{n}\right) J T_{n} x_{n}\right], \quad T_{n}=T_{n(\bmod ) N}, \\
& y_{n}=J^{-1}\left[\alpha_{n} J x_{1}+\left(1-\alpha_{n}\right) J z_{n}\right], \\
& C_{n+1}=\left\{z \in C_{n}: \phi\left(z, y_{n}\right) \leq \phi\left(z, x_{n}\right)+\alpha_{n} \phi\left(z, x_{1}\right)\right. \\
& \left.\quad+\left(1-\alpha_{n}\right)\left[\beta_{n} \phi\left(z, x_{n-1}\right)+\left(1-\beta_{n}\right) \phi\left(z, T_{n} x_{n}\right)\right]\right\}, \\
& x_{n+1}=\Pi_{C_{n+1}} x_{1}, \quad n \in \mathbb{N} \cup\{0\} .
\end{aligned}
$$

Let $\left\{\alpha_{n}\right\}_{n \in \mathbb{N} \cup\{0\}}$ and $\left\{\beta_{n}\right\}_{n \in \mathbb{N} \cup\{0\}}$ be sequences in $[0,1)$ such that $\lim _{n \rightarrow \infty} \alpha_{n}=0$ and $\lim _{n \rightarrow \infty} \beta_{n}=0$. Then $\left\{x_{n}\right\}_{n \in \mathbb{N}}$ converge strongly to $\Pi_{F} x_{1}$ as $n \rightarrow \infty$.

1.1. Some Facts about Gradients. For any convex function $g$ : $E \rightarrow(-\infty,+\infty]$, we denote the domain of $g$ by dom $g=$ $\{x \in E: g(x)<\infty\}$. For any $x \in$ int dom $g$ and any $y \in E$, we denote by $g^{o}(x, y)$ the right-hand derivative of $g$ at $x$ in the direction $y$; that is,

$$
g^{o}(x, y)=\lim _{t \downarrow 0} \frac{g(x+t y)-g(x)}{t} .
$$

The function $g$ is said to be Gâteaux differentiable at $x$ if $\lim _{t \rightarrow 0}((g(x+t y)-g(x)) / t)$ exists for any $y$. In this case, $g^{o}(x, y)$ coincides with $\nabla g(x)$, the value of the gradient $\nabla g$ of $g$ at $x$. The function $g$ is said to be Gâteaux differentiable if it is Gâteaux differentiable everywhere. The function $g$ is said to be Fréchet differentiable at $x$ if this limit is attained uniformly in $\|y\|=1$. The function $g$ is Fréchet differentiable at $x \in E$ (see, e.g., [18, p. 13] or $[19$, p. 508]) if for all $\epsilon>0$, there exists $\delta>0$ such that $\|y-x\| \leq \delta$ implies that

$$
|g(y)-g(x)-\langle y-x, \nabla g(x)\rangle| \leq \epsilon\|y-x\| .
$$

The function $g$ is said to be Fréchet differentiable if it is Fréchet differentiable everywhere. It is well known that if a continuous convex function $g: E \rightarrow \mathbb{R}$ is Gâteaux differentiable, then $\nabla g$ is norm-to-weak ${ }^{*}$ continuous (see, e.g., [18, Proposition 1.1.10]). Also, it is known that if $g$ is Fréchet differentiable, then $\nabla g$ is norm-to-norm continuous (see, $[19, \mathrm{p} .508]$ ). The function $g$ is said to be strongly coercive if

$$
\lim _{\left\|x_{n}\right\| \rightarrow \infty} \frac{g\left(x_{n}\right)}{\left\|x_{n}\right\|}=\infty
$$

It is also said to be bounded if $g(U)$ is bounded for each bounded subset $U$ of $E$. Finally, $g$ is said to be uniformly Fréchet differentiable on a subset $X$ of $E$ if the limit (9) is attained uniformly for all $x \in X$ and $\|y\|=1$.
1.2. Some Facts about Legendre Functions. Let $E$ be a reflexive Banach space. For any proper, lower semicontinuous, and convex function $g: E \rightarrow(-\infty,+\infty]$, the conjugate function $g^{*}$ of $g$ is defined by

$$
g^{*}\left(x^{*}\right)=\sup _{x \in E}\left\{\left\langle x, x^{*}\right\rangle-g(x)\right\}, \quad \forall x^{*} \in E^{*} .
$$

It is well known that $g(x)+g^{*}\left(x^{*}\right) \geq\left\langle x, x^{*}\right\rangle$ for all $\left(x, x^{*}\right) \in$ $E \times E^{*}$. It is also known that $\left(x, x^{*}\right) \in \partial g$ is equivalent to

$$
g(x)+g^{*}\left(x^{*}\right)=\left\langle x, x^{*}\right\rangle .
$$

Here, $\partial g$ is the subdifferential of $g[20,21]$. We also know that if $g: E \rightarrow(-\infty,+\infty]$ is a proper, lower semicontinuous, and convex function, then $g^{*}: E^{*} \rightarrow(-\infty,+\infty]$ is a proper, weak* lower semicontinuous, and convex function; see [2] for more details on convex analysis.

The function $g: E \rightarrow(-\infty,+\infty]$ is called Legendre if it satisfies the following conditions:

(i) $\partial g$ is both locally bounded and single-valued on its domain;

(ii) $(\partial g)^{-1}$ is locally bounded on its domain and $g$ is strictly convex on every convex subset of dom $\partial g$.

For more details, we refer to [22].

If $E$ is a reflexive Banach space and $g: E \rightarrow(-\infty,+\infty]$ is a Legendre function, then in view of [23];

$$
\begin{gathered}
\nabla g^{*}=(\nabla g)^{-1}, \quad \operatorname{ran} \nabla g=\operatorname{dom} g^{*}=\text { int dom } g^{*}, \\
\operatorname{ran} \nabla g=\text { int dom } g .
\end{gathered}
$$

Examples of Legendre functions are given in [22, 24]. One important and interesting Legendre function is $(1 / s)\|\cdot\|^{s}(1<s<\infty)$, where the Banach space $E$ is smooth and strictly convex and, in particular, a Hilbert space.

1.3. Some Facts about Bregman Distances. Let $E$ be a Banach space and let $E^{*}$ be the dual space of $E$. Let $g: E \rightarrow \mathbb{R}$ be a convex and Gâteaux differentiable function. Then the Bregman distance $[25,26]$ corresponding to $g$ is the function $D_{g}: E \times E \rightarrow \mathbb{R}$ defined by

$$
D_{g}(x, y)=g(x)-g(y)-\langle x-y, \nabla g(y)\rangle, \quad \forall x, y \in E .
$$

It is clear that $D_{g}(x, y) \geq 0$ for all $x, y \in E$. In that case when $E$ is a smooth Banach space, setting $g(x)=\|x\|^{2}$ for all $x \in E$, we obtain that $\nabla g(x)=2 J x$ for all $x \in E$ and hence $D_{g}(x, y)=\phi(x, y)$ for all $x, y \in E$.

Let $E$ be a Banach space and let $C$ be a nonempty, convex, and subset of $E$. Let $g: E \rightarrow \mathbb{R}$ be a convex and Gâteaux differentiable function. Then, we know from $[27,28]$ that for $x \in E$ and $x_{0} \in C$,

$$
\begin{array}{r}
D_{g}\left(x_{0}, x\right)=\min _{y \in C} D_{g}(y, x) \\
\text { iff }\left\langle y-x_{0}, \nabla g(x)-\nabla g\left(x_{0}\right)\right\rangle \leq 0, \\
\forall y \in C .
\end{array}
$$


Furthermore, if $C$ is a nonempty, closed, and convex subset of a reflexive Banach space $E$ and $g: E \rightarrow \mathbb{R}$ is a strongly coercive Bregman function, then for each $x \in E$, there exists a unique $x_{0} \in C$ such that

$$
D_{g}\left(x_{0}, x\right)=\min _{y \in C} D_{g}(y, x) .
$$

The Bregman projection $\operatorname{proj}_{C}^{g}$ from $E$ onto $C$ is defined by $\operatorname{proj}_{C}^{g}(x)=x_{0}$ for all $x \in E$. It is also well known that proj ${ }_{C}^{g}$ has the following property [27]:

$$
D_{g}\left(y, \operatorname{proj}_{C}^{g} x\right)+D_{g}\left(\operatorname{proj}_{C}^{g} x, x\right) \leq D_{g}(y, x)
$$

for all $y \in C$ and $x \in E$ (see [18] for more details). Let $E$ be a reflexive Banach space, let $g: E \rightarrow \mathbb{R}$ be a strongly coercive Bregman function, and let $D_{g}: E \times E \rightarrow \mathbb{R}$ be the Bregman distance corresponding to $g$. Then, $g^{*}: E^{*} \rightarrow \mathbb{R}$ is convex and Gâteaux differentiable [29]. Let $D_{g^{*}}: E^{*} \times E^{*} \rightarrow \mathbb{R}$ be the function defined by

$$
D_{g^{*}}\left(x^{*}, y^{*}\right)=g^{*}\left(x^{*}\right)-g^{*}\left(y^{*}\right)-\left\langle\nabla g^{*}\left(y^{*}\right), x^{*}-y^{*}\right\rangle
$$

for $x^{*}, y^{*} \in E^{*}$, where $\nabla g^{*}$ is the gradient of $g^{*}$. We know from [28] that

$$
D_{g^{*}}(\nabla g(x), \nabla g(y))=D_{g}(y, x)
$$

for all $x, y \in E$. We have from the definition of $D_{g^{*}}$ that

$$
\begin{array}{r}
D_{g^{*}}\left(x^{*}, y^{*}\right)=D_{g^{*}}\left(x^{*}, z^{*}\right)+D_{g^{*}}\left(z^{*}, y^{*}\right) \\
+\left\langle\nabla g^{*}\left(x^{*}\right)-\nabla g^{*}\left(z^{*}\right), z^{*}-y^{*}\right\rangle, \\
\forall x^{*}, y^{*}, z^{*} \in E^{*} .
\end{array}
$$

In particular,

$$
\begin{aligned}
& D_{g^{*}}\left(x^{*}, y^{*}\right)=-D_{g^{*}}\left(y^{*}, x^{*}\right) \\
&+\left\langle\nabla g^{*}\left(y^{*}\right)-\nabla g^{*}\left(x^{*}\right), y^{*}-x^{*}\right\rangle \\
& \forall x^{*}, y^{*} \in E^{*}
\end{aligned}
$$

Indeed, there exist $x, y, z \in E$ such that $\nabla g(x)=x^{*}, \nabla g(y)=$ $y^{*}$ and $\nabla g(z)=z^{*}$. Therefore,

$$
\begin{aligned}
D_{g^{*}}\left(x^{*}, y^{*}\right)= & D_{g^{*}}(\nabla g(x), \nabla g(y))=D_{g}(y, x) \\
= & D_{g}(y, z)+D_{g}(z, x) \\
& +\langle y-z, \nabla g(z)-\nabla g(x)\rangle \\
= & D_{g^{*}}(\nabla g(z), \nabla g(y))+\phi_{*}(\nabla g(x), \nabla g(z)) \\
& +\left\langle\nabla g^{*}\left(y^{*}\right)-\nabla g^{*}\left(z^{*}\right), z^{*}-x^{*}\right\rangle \\
= & D_{g^{*}}\left(z^{*}, y^{*}\right)+D_{g^{*}}\left(x^{*}, z^{*}\right) \\
& +\left\langle\nabla g^{*}\left(x^{*}\right)-\nabla g^{*}\left(z^{*}\right), z^{*}-y^{*}\right\rangle .
\end{aligned}
$$

1.4. Some Facts about Uniformly Convex Functions. Let $E$ be a Banach space and let $B_{r}:=\{z \in E:\|z\| \leq r\}$ for all $r>0$. Then a function $g: E \rightarrow \mathbb{R}$ is said to be uniformly convex on bounded subsets of $E([29$, pp. 203,221$])$ if $\rho_{r}(t)>0$ for all $r, t>0$, where $\rho_{r}:[0,+\infty) \rightarrow[0, \infty]$ is defined by

$$
\begin{aligned}
\rho_{r}(t)=\inf _{x, y \in B_{r},\|x-y\|=t, \alpha \in(0,1)}( & (\alpha g(x)+(1-\alpha) g(y) \\
& -g(\alpha x+(1-\alpha) y)) \\
& \left.\times(\alpha(1-\alpha))^{-1}\right)
\end{aligned}
$$

for all $t \geq 0$. The function $\rho_{r}$ is called the gauge of uniform convexity of $g$. The function $g$ is also said to be uniformly smooth on bounded subsets of $E$ ([29, pp. 207, 221]) if $\lim _{t \downarrow 0}\left(\sigma_{r}(t) / t\right)=0$ for all $r>0$, where $\sigma_{r}:[0,+\infty) \rightarrow$ $[0, \infty]$ is defined by

$$
\begin{aligned}
& \sigma_{r}(t) \\
& =\sup _{x \in B_{r}, y \in S_{E}, \alpha \in(0,1)}( \\
& \\
& +(1-\alpha) g(x+\alpha t y)-g(x)) \\
& \left.\quad \times(\alpha(1-\alpha))^{-1}\right)
\end{aligned}
$$

for all $t \geq 0$.

1.5. Some Facts about Resolvents. Let $E$ be a Banach space with the norm $\|\cdot\|$ and the dual space $E^{*}$. Let $A: E \rightarrow 2^{E^{*}}$ be a set-valued mapping. We define the domain and range of $A$ by $\operatorname{dom} A=\{x \in E: A x \neq \varnothing\}$ and $\operatorname{ran} A=$ $\cup_{x \in E} A x$, respectively. The graph of $A$ is denoted by $G(A)=$ $\left\{\left(x, x^{*}\right) \in E \times E^{*}: x^{*} \in A x\right\}$. The mapping $A \subset E \times E^{*}$ is said to be monotone $[30,31]$ if $\left\langle x-y, x^{*}-y^{*}\right\rangle \geq 0$ whenever $\left(x, x^{*}\right),\left(y, y^{*}\right) \in A$. It is also said to be maximal monotone [20] if its graph is not contained in the graph of any other monotone operator on $E$. If $A \subset E \times E^{*}$ is maximal monotone, then we can show that the set $A^{-1} 0=\{z \in E: 0 \in$ $\mathrm{A} z\}$ is closed and convex. Let $E$ be a reflexive Banach space with the dual space $E^{*}$ and let $g: E \rightarrow(-\infty,+\infty]$ be a proper, lower semicontinuous, and convex function. Let $A$ be a maximal monotone operator from $E$ to $E^{*}$. For any $r>0$, let the mapping $\operatorname{Res}_{r A}^{g}: E \rightarrow \operatorname{dom} A$ be defined by

$$
\operatorname{Res}_{r A}^{g}=(\nabla g+r A)^{-1} \nabla g .
$$

The mapping $\operatorname{Res}_{r A}^{g}$ is called the $g$-resolvent of $A$ (see [32]). It is well known that $A^{-1}(0)=F\left(\operatorname{Res}_{r A}^{g}\right.$ ) for each $r>0$ (for more details, see, e.g., $[1,33])$.

1.6. Some Facts about Bregman Quasinonexpansive Mappings. Let $C$ be a nonempty, closed, and convex subset of a reflexive Banach space $E$. Let $g: E \rightarrow(-\infty,+\infty)$ be a proper, lower semicontinuous, and convex function. Recall that a mapping $T: C \rightarrow C$ is said to be Bregman quasinonexpansive, if $F(T) \neq \varnothing$ and

$$
D_{g}(p, T x) \leq D_{g}(p, x), \quad \forall x \in C, p \in F(T) .
$$

Nontrivial examples of such mappings are given in [34]. 
A mapping $T: C \rightarrow C$ is said to be Bregman relatively nonexpansive if the following conditions are satisfied:

(1) $F(T)$ is nonempty;

(2) $D_{g}(p, T v) \leq D_{g}(p, v), \forall p \in F(T), v \in C$;

(3) $\widehat{F}(T)=F(T)$.

A mapping $T$ : $C \rightarrow C$ is said to be Bregman weakly relatively nonexpansive if the following conditions are satisfied:

(1) $F(T)$ is nonempty;

(2) $D_{g}(p, T v) \leq D_{g}(p, v), \forall p \in F(T), v \in C$;

(3) $\widetilde{F}(T)=F(T)$.

It is clear that any Bregman relatively nonexpansive mapping is a Bregman quasinonexpansive mapping. It is also obvious that every Bregman relatively nonexpansive mapping is a Bregman weakly relatively nonexpansive mapping, but the converse is not true in general. Indeed, for any mapping $T$ : $C \rightarrow C$, we have $F(T) \subset \widetilde{F}(T) \subset \widehat{F}(T)$. If $T$ is Bregman relatively nonexpansive, then $F(T)=\widetilde{F}(T)=\widehat{F}(T)$. It is easy to verify that any closed mapping $T: C \rightarrow C$ is a Bregman weakly relatively nonexpansive mapping. To this end, let $\left\{x_{n}\right\}_{n \in \mathbb{N}}$ be a sequence of $C$ such that $x_{n} \rightarrow x \in C$ and $\left\|x_{n}-T x_{n}\right\| \rightarrow 0$ as $n \rightarrow \infty$. This implies that $T x_{n} \rightarrow x \in C$ as $n \rightarrow \infty$. From the closedness of $T$, we conclude that $x \in F(T)$. Below we show that there exists a Bregman weakly relatively nonexpansive mapping which is neither a Bregman relatively nonexpansive mapping nor a closed mapping.

Example 4. Let $E=l^{2}$, where

$$
\begin{aligned}
& l^{2}=\left\{\sigma=\left(\sigma_{1}, \sigma_{2}, \ldots, \sigma_{n}, \ldots\right): \sum_{n=1}^{\infty}\left\|\sigma_{n}\right\|^{2}<\infty\right\}, \\
& \|\sigma\|=\left(\sum_{n=1}^{\infty}\left\|\sigma_{n}\right\|^{2}\right)^{1 / 2},
\end{aligned}
$$

$\forall \sigma \in l^{2}$

$$
\begin{array}{r}
\langle\sigma, \eta\rangle=\sum_{n=1}^{\infty} \sigma_{n} \eta_{n}, \quad \forall \delta=\left(\sigma_{1}, \sigma_{2}, \ldots, \sigma_{n}, \ldots\right), \\
\eta=\left(\eta_{1}, \eta_{2}, \ldots, \eta_{n}, \ldots\right) \in l^{2} .
\end{array}
$$

Let $\left\{x_{n}\right\}_{n \in \mathbb{N} \cup\{0\}} \subset E$ be a sequence defined by

$$
\begin{gathered}
x_{0}=(1,0,0,0, \ldots) \\
x_{1}=(1,1,0,0,0, \ldots) \\
x_{2}=(1,0,1,0,0,0, \ldots) \\
x_{3}=(1,0,0,1,0,0,0, \ldots) \\
\ldots \\
x_{n}=\left(\sigma_{n, 1}, \sigma_{n, 2}, \ldots, \sigma_{n, k}, \ldots\right) \\
\ldots,
\end{gathered}
$$

where

$$
\sigma_{n, k}= \begin{cases}1 & \text { if } k=1, n+1, \\ 0 & \text { if } k \neq 1, k \neq n+1,\end{cases}
$$

for all $n \in \mathbb{N}$. It is clear that the sequence $\left\{x_{n}\right\}_{n \in \mathbb{N}}$ converges weakly to $x_{0}$. Indeed, for any $\Lambda=\left(\lambda_{1}, \lambda_{2}, \ldots, \lambda_{n}, \ldots\right) \in l^{2}=$ $\left(l^{2}\right)^{*}$, we have

$$
\Lambda\left(x_{n}-x_{0}\right)=\left\langle x_{n}-x_{0}, \Lambda\right\rangle=\sum_{k=2}^{\infty} \lambda_{k} \sigma_{n, k} \longrightarrow 0
$$

as $n \rightarrow \infty$. It is also obvious that $\left\|x_{n}-x_{m}\right\|=\sqrt{2}$ for any $n \neq m$ with $n, m$ sufficiently large. Thus, $\left\{x_{n}\right\}_{n \in \mathbb{N}}$ is not a Cauchy sequence. Let $k$ be an even number in $\mathbb{N}$ and let $g: E \rightarrow \mathbb{R}$ be defined by

$$
g(x)=\frac{1}{k}\|x\|^{k}, \quad x \in E .
$$

It is easy to show that $\nabla g(x)=J_{k}(x)$ for all $x \in E$, where

$$
J_{k}(x)=\left\{x^{*} \in E^{*}:\left\langle x, x^{*}\right\rangle=\|x\|\left\|x^{*}\right\|,\left\|x^{*}\right\|=\|x\|^{k-1}\right\} .
$$

It is also obvious that

$$
J_{k}(\lambda x)=\lambda^{k-1} J_{k}(x), \quad \forall x \in E, \lambda \in \mathbb{R} .
$$

Now, we define a mapping $T: E \rightarrow E$ by

$$
T(x)= \begin{cases}\frac{n}{n+1} x, & \text { if } x=x_{n} ; \\ -x, & \text { if } x \neq x_{n} .\end{cases}
$$

Then $F(T)=\{0\}$ and $T$ is a Bregman weakly relatively nonexpansive mapping which is not a Bregman relatively nonexpansive mapping; see [35] for more details. Now, we prove that $T$ is not a closed mapping. Indeed, let $y_{n}=(1+$ $1 / n) x_{2}$ for all $n$ in $\mathbb{N}$. Then $y_{n} \rightarrow x_{2}$ as $n \rightarrow \infty, T y_{n}=$ $-(1+1 / n) x_{2} \rightarrow-x_{2}\left(\right.$ since $y_{n} \neq x_{m}$ for all $\left.n, m \in \mathbb{N}\right)$, but $T x_{2}=(2 / 3) x_{2} \neq-x_{2}$.

An example of a Bregman quasinonexpansive mapping which is neither a Bregman relatively nonexpansive mapping 
nor a Bregman weakly relatively nonexpansive mapping can be found in [35].

In this paper, we investigate the problem of finding zeros of mappings $A: E \rightarrow 2^{E^{*}}$; that is, find $x \in \operatorname{dom} A$ such that

$$
0^{*} \in A x \text {. }
$$

Recently, Sabach [36] proved the following two strong convergence theorems for the products of finitely many resolvents of maximal monotone operators in a reflexive Banach space.

Theorem 5. Let $E$ be a reflexive Banach space and let $A_{i}$ : $E \rightarrow 2^{E^{*}}, i=1,2, \ldots, N$, be $N$ maximal monotone operators such that $Z:=\cap_{i=1}^{N} A_{i}^{-1}\left(0^{*}\right) \neq \varnothing$. Let $g: E \rightarrow \mathbb{R}$ be a Legendre function that is bounded, uniformly Fréchet differentiable, and totally convex on bounded subsets of E. Let $\left\{x_{n}\right\}_{n \in \mathbb{N}}$ be a sequence defined by the following iterative algorithm:

$$
\begin{aligned}
x_{0} & \in E \text { chosen arbitrarily, } \\
y_{n} & =\operatorname{Res}_{\lambda_{n}^{N} A_{N}}^{g}, \ldots, \operatorname{Res}_{\lambda_{n}^{1} A_{1}}^{g}\left(x_{n}+e_{n}\right), \\
C_{n} & =\left\{z \in E: D_{g}\left(z, y_{n}\right) \leq D_{g}\left(z, x_{n}+e_{n}\right)\right\}, \\
Q_{n} & =\left\{z \in E:\left\langle z-x_{n}, \nabla g\left(x_{0}\right)-\nabla g\left(x_{n}\right)\right\rangle \leq 0\right\}, \\
x_{n+1} & =\operatorname{proj}_{C_{n} \cap Q_{n}}^{g} x_{0} \text { and } n \in \mathbb{N} \cup\{0\} .
\end{aligned}
$$

If, for each $i=1,2, \ldots, N$, $\liminf _{n \rightarrow \infty} \lambda_{n}^{i}>0$, and the sequences of errors $\left\{e_{n}^{i}\right\}_{n \in \mathbb{N}} \subset$ E satisfy $\liminf _{n \rightarrow \infty} e_{n}^{i}=0$, then each such sequence $\left\{x_{n}\right\}_{n \in \mathbb{N}}$ converges strongly to $\operatorname{proj}_{Z}^{g}\left(x_{0}\right)$ as $n \rightarrow \infty$.

Theorem 6. Let $E$ be a reflexive Banach space and let $A_{i}$ : $E \rightarrow 2^{E^{*}}, i=1,2, \ldots, N$, be $N$ maximal monotone operators such that $Z:=\cap_{i=1}^{N} A_{i}^{-1}\left(0^{*}\right) \neq \varnothing$. Let $g: E \rightarrow \mathbb{R}$ be a Legendre function that is bounded, uniformly Fréchet differentiable, and totally convex on bounded subsets of E. Let $\left\{x_{n}\right\}_{n \in \mathbb{N}}$ be a sequence defined by the following iterative algorithm:

$$
\begin{aligned}
x_{0} & \in E \text { chosen arbitrarily, } \\
H_{0} & =E, \\
y_{n} & =\operatorname{Res}_{\lambda_{n}^{N} A_{N}}^{g}, \ldots, \operatorname{Res}_{\lambda_{n}^{1} A_{1}}^{g}\left(x_{n}+e_{n}\right), \\
H_{n+1} & =\left\{z \in H_{n}: D_{g}\left(z, y_{n}\right) \leq D_{g}\left(z, x_{n}+e_{n}\right)\right\}, \\
x_{n+1} & =\operatorname{proj}_{H_{n+1}}^{g} x_{0} \text { and } n \in \mathbb{N} \cup\{0\} .
\end{aligned}
$$

If, for each $i=1,2, \ldots, N$, $\liminf _{n \rightarrow \infty} \lambda_{n}^{i}>0$, and the sequences of errors $\left\{e_{n}^{i}\right\}_{n \in \mathbb{N}} \subset$ E satisfy $\lim _{\inf }{ }_{n \rightarrow \infty} e_{n}^{i}=0$, then each such sequence $\left\{x_{n}\right\}_{n \in \mathbb{N}}$ converges strongly to $\operatorname{proj}_{Z}^{g}\left(x_{0}\right)$ as $n \rightarrow \infty$.

The approximation of fixed points of Bregman nonexpansive type mappings via Bregman distances has been studied in the last ten years and much intensively in the last five years.
For some recent articles on the existence and the construction of fixed points for Bregman nonexpansive type mappings, we refer the readers to [36-40].

But it is worth mentioning that, in all the above results for Bregman nonexpansive type mappings, the assumption $\widehat{F}(T)=F(T)$ is imposed on the map $T$ or the closedness of $T$ is required. So, the following question arises naturally in a Banach space setting.

Question 1. Is it possible to obtain strong convergence of modified Mann's type schemes to a common fixed point of an infinite family of Bregman quasinonexpansive mappings $\left\{T_{j}\right\}_{j \in \mathbb{N}}$ without imposing the closedness assumption, the uniformly continuity assumption, or the assumption $\widehat{F}\left(T_{j}\right)=$ $F\left(T_{j}\right)$ on the mapping $T_{j}$ ?

In this paper, using Bregman functions, we introduce a new hybrid iterative scheme for finding common fixed points of an infinite family of Bregman weakly relatively nonexpansive mappings in Banach spaces. We prove a strong convergence theorem for the sequence produced by the method. No closedness assumption is imposed on a mapping $T: C \rightarrow C$, where $C$ is a closed and convex subset of a reflexive Banach space $E$. Consequently, the above question is answered in the affirmative in reflexive Banach space setting. Furthermore, we apply our method to solve a system of equilibrium problems in reflexive Banach spaces. Some application of our results to the problem of finding a minimizer of a continuously Fréchet differentiable and convex function in a Banach space is presented. Our results improve and generalize many known results in the current literature; see, for example, [8, 11-14, 41-48].

\section{Preliminaries}

In this section, we begin by recalling some preliminaries and lemmas which will be used in the sequel.

Definition 7 (see [19]). Let $E$ be a Banach space. The function $g: E \rightarrow \mathbb{R}$ is said to be a Bregman function if the following conditions are satisfied:

(1) $g$ is continuous, strictly convex, and Gâteaux differentiable;

(2) the set $\left\{y \in E: D_{g}(x, y) \leq r\right\}$ is bounded for all $x \in E$ and $r>0$.

The following lemma follows from Butnariu and Iusem [18] and Zălinescu [29].

Lemma 8. Let $E$ be a reflexive Banach space and let $g: E \rightarrow$ $\mathbb{R}$ be a strongly coercive Bregman function. Then

(1) $\nabla g: E \rightarrow E^{*}$ is one-to-one, onto and norm-to-weak ${ }^{*}$ continuous;

(2) $\langle x-y, \nabla g(x)-\nabla g(y)\rangle=0$ if and only if $x=y$;

(3) $\left\{x \in E: D_{g}(x, y) \leq r\right\}$ is bounded for all $y \in E$ and $r>0$; 
(4) dom $g^{*}=E^{*}, g^{*}$ is Gâteaux differentiable and $\nabla g^{*}=$ $(\nabla g)^{-1}$. 3.6.4].

We know the following two results; see [29, Proposition

Theorem 9. Let $E$ be a reflexive Banach space and let $g: E \rightarrow$ $\mathbb{R}$ be a convex function which is bounded on bounded subsets of $E$. Then the following assertions are equivalent:

(1) $g$ is strongly coercive and uniformly convex on bounded subsets of $E$;

(2) dom $g^{*}=E^{*}, g^{*}$ is bounded on bounded subsets and uniformly smooth on bounded subsets of $E^{*}$;

(3) dom $g^{*}=E^{*}, g^{*}$ is Fréchet differentiable and $\nabla g^{*}$ is uniformly norm-to-norm continuous on bounded subsets of $E^{*}$.

Theorem 10. Let $E$ be a reflexive Banach space and let $g$ : $E \rightarrow \mathbb{R}$ be a continuous convex function which is strongly coercive. Then the following assertions are equivalent:

(1) $g$ is bounded on bounded subsets and uniformly smooth on bounded subsets of $E$;

(2) $g^{*}$ is Fréchet differentiable and $\nabla g^{*}$ is uniformly normto-norm continuous on bounded subsets of $E^{*}$;

(3) dom $g^{*}=E^{*}, g^{*}$ is strongly coercive and uniformly convex on bounded subsets of $E^{*}$.

Let $E$ be a Banach space and let $g: E \rightarrow \mathbb{R}$ be a convex and Gâteaux differentiable function. Then the Bregman distance [48] (see also $[25,26]$ ) satisfies the three point identity that is

$$
\begin{aligned}
D_{g}(x, z)= & D_{g}(x, y)+D_{g}(y, z) \\
& +\langle x-y, \nabla g(y)-\nabla g(z)\rangle, \quad \forall x, y, z \in E .
\end{aligned}
$$

In particular, it can be easily seen that

$$
\begin{aligned}
D_{g}(x, y)= & -D_{g}(y, x) \\
& +\langle y-x, \nabla g(y)-\nabla g(x)\rangle, \quad \forall x, y \in E .
\end{aligned}
$$

Indeed, by letting $z=x$ in (39) and taking into account that $D_{g}(x, x)=0$, we get the desired result.

Lemma 11 (see [39]). Let $E$ be a Banach space and let $g: E \rightarrow$ $\mathbb{R}$ be a Gâteaux differentiable function which is uniformly convex on bounded subsets of E. Let $\left\{x_{n}\right\}_{n \in \mathbb{N}}$ and $\left\{y_{n}\right\}_{n \in \mathbb{N}}$ be bounded sequences in $E$. Then the following assertions are equivalent:

(1) $\lim _{n \rightarrow \infty} D_{g}\left(x_{n}, y_{n}\right)=0$;

(2) $\lim _{n \rightarrow \infty}\left\|x_{n}-y_{n}\right\|=0$. 38]).
Lemma 12. Let $E$ be a reflexive Banach space let $g: E \rightarrow$ $\mathbb{R}$ be a strongly coercive Bregman function and $V$ the function defined by

$V\left(x, x^{*}\right)=g(x)-\left\langle x, x^{*}\right\rangle+g^{*}\left(x^{*}\right), \quad \forall x \in E, \forall x^{*} \in E^{*}$.

Then the following assertions hold:

(1) $D_{g}\left(x, \nabla g^{*}\left(x^{*}\right)\right)=V\left(x, x^{*}\right)$ for all $x \in E$ and $x^{*} \in E^{*}$;

(2) $V\left(x, x^{*}\right)+\left\langle\nabla g^{*}\left(x^{*}\right)-x, y^{*}\right\rangle \leq V\left(x, x^{*}+y^{*}\right)$ for all $x \in E$ and $x^{*}, y^{*} \in E^{*}$.

The following lemma which is a generalization of Lemma 3.2 in [50] plays a key role in our results.

Lemma 13 (see [17]). Let $C$ be a subset of a real Banach space $E$ and let $\left\{T_{n}\right\}_{n \in \mathbb{N}}$ be a family of mappings from $C$ into $E$. Suppose that for any bounded subset $B$ of $C$, there exists a continuous increasing function $h_{B}:[0, \infty) \rightarrow[0, \infty)$ such that $h_{B}(0)=0$ and $\lim _{k, l \rightarrow \infty} \theta_{l}^{k}=0$, where $\theta_{l}^{k}:=\sup \left\{h_{B}\left(\left\|T_{k} z-T_{l} z\right\|\right): z \epsilon\right.$ $B\}<\infty$, for all $k, l \in \mathbb{N}$. Then, for each $x \in C,\left\{T_{n} x\right\}_{n \in \mathbb{N}}$ converges strongly to some point of E. Moreover, let the mapping $T$ be defined by

$$
T x=\lim _{n \rightarrow \infty} T_{n} x, \quad \forall x \in C .
$$

Then, $\lim \sup _{n \rightarrow \infty}\left\{h_{B}\left(\left\|T_{n} z-T z\right\|\right): z \in B\right\}=0$.

Lemma 14. Let $E$ be a Banach space and let $g: E \rightarrow \mathbb{R}$ be a convex function which is uniformly convex on bounded subsets of $E$. Let $s>0$ be a constant, $B_{s}:=\{z \in E:\|z\| \leq s\}$, $B_{s}^{*}:=\left\{z^{*} \in E^{*}:\left\|z^{*}\right\| \leq s\right\}$, let $\rho_{s}$ be the gauge of uniform convexity of $g$, and let $\rho_{s}^{*}$ be the gauge of uniform convexity of $g^{*}$, respectively. Then

(i) for any $x, y \in B_{s}$ and $\alpha \in(0,1)$

$$
\begin{aligned}
& g(\alpha x+(1-\alpha) y) \\
& \leq \alpha g(x)+(1-\alpha) g(y) \\
& \quad-\alpha(1-\alpha) \rho_{s}(\|x-y\|) ;
\end{aligned}
$$

(ii) for any $x, y \in B_{s}$

$$
\rho_{s}(\|x-y\|) \leq D_{g}(x, y)
$$

(iii) if, in addition, $g$ is bounded on bounded subsets and uniformly convex on bounded subsets of $E$, then, for any $x \in E, y^{*}, z^{*} \in B_{s}$ and $\alpha \in(0,1)$

$$
\begin{aligned}
& V\left(x, \alpha y^{*}+(1-\alpha) z^{*}\right) \\
& \leq \alpha V\left(x, y^{*}\right)+(1-\alpha) V\left(x, z^{*}\right) \\
& -\alpha(1-\alpha) \rho_{s}^{*}\left(\left\|y^{*}-z^{*}\right\|\right) ;
\end{aligned}
$$

(iv) if, in addition, $g$ is bounded on bounded subsets, uniformly convex, and uniformly smooth on bounded subsets of $E$, then, for any $x \in E, y^{*}, z^{*} \in B_{s}$

$$
\rho_{s}^{*}\left(\left\|x^{*}-y^{*}\right\|\right) \leq D_{g^{*}}\left(x^{*}, y^{*}\right) .
$$


Proof. In view of (24), we get (i). Let us prove (ii). If $x, y \in B_{s}$ and $\alpha \in(0,1)$, then we obtain

$$
\begin{aligned}
& \frac{g(\alpha x+(1-\alpha) y)-g(y)}{\alpha} \\
& \quad \leq g(x)-g(y)-(1-\alpha) \rho_{s}(\|x-y\|) .
\end{aligned}
$$

Letting $\alpha \rightarrow 0$ in the above inequality, we arrive at

$$
\langle x-y, \nabla g(y)\rangle \leq g(x)-g(y)-\rho_{s}(\|x-y\|) .
$$

This implies that

$$
\rho_{s}(\|x-y\|) \leq D_{g}(x, y) .
$$

(iii) Let $x \in E, y^{*}, z^{*} \in B_{s}$, and $\alpha \in(0,1)$. Then

$$
\begin{aligned}
V(x, & \left.\alpha y^{*}+(1-\alpha) z^{*}\right) \\
= & g(x)-\left\langle x, \alpha y^{*}+(1-\alpha) z^{*}\right\rangle \\
& +g^{*}\left(\alpha y^{*}+(1-\alpha) z^{*}\right) \\
\leq & g(x)-\alpha\left\langle x, y^{*}\right\rangle-(1-\alpha)\left\langle x, z^{*}\right\rangle \\
& +\alpha g^{*}\left(y^{*}\right)+(1-\alpha) g^{*}\left(z^{*}\right) \\
& -\alpha(1-\alpha) \rho_{s}^{*}\left(\left\|y^{*}-z^{*}\right\|\right) \\
= & \alpha g(x)+(1-\alpha) g(x)-\alpha\left\langle x, y^{*}\right\rangle \\
& -(1-\alpha)\left\langle x, z^{*}\right\rangle \\
& +\alpha g^{*}\left(y^{*}\right)+(1-\alpha) g^{*}\left(z^{*}\right) \\
& -\alpha(1-\alpha) \rho_{s}^{*}\left(\left\|y^{*}-z^{*}\right\|\right) \\
= & \alpha\left[g(x)-\left\langle x, y^{*}\right\rangle+g^{*}\left(y^{*}\right)\right] \\
& +(1-\alpha)\left[g(x)-\left\langle x, z^{*}\right\rangle+g^{*}\left(z^{*}\right)\right] \\
& -\alpha(1-\alpha) \rho_{s}^{*}\left(\left\|y^{*}-z^{*}\right\|\right) \\
= & \alpha V\left(x, y^{*}\right)+(1-\alpha) V\left(x, z^{*}\right) \\
& -\alpha(1-\alpha) \rho_{s}^{*}\left(\left\|y^{*}-z^{*}\right\|\right) .
\end{aligned}
$$

(iv) Since $g$ is uniformly smooth on bounded subsets of $E, g^{*}$ is uniformly convex on bounded subsets of $E$. Then, in view of (i), there exists a continuous, strictly increasing, and convex function $\rho_{s}^{*}:[0, \infty) \rightarrow[0, \infty)$ such that

$$
\begin{aligned}
& g^{*}\left(\alpha x^{*}+(1-\alpha) y^{*}\right) \\
& \leq \alpha g^{*}\left(x^{*}\right)+(1-\alpha) g^{*}\left(y^{*}\right) \\
& \quad-\alpha(1-\alpha) \rho_{s}^{*}\left(\left\|x^{*}-y^{*}\right\|\right)
\end{aligned}
$$

for all $x^{*}, y^{*} \in B_{s}^{*}$ and all $\alpha \in(0,1)$. If $x^{*}, y^{*} \in B_{s}^{*}$, then we obtain

$$
\begin{aligned}
& \frac{g^{*}\left(\alpha x^{*}+(1-\alpha) y^{*}\right)-g^{*}\left(y^{*}\right)}{\alpha} \\
& \quad \leq g^{*}\left(x^{*}\right)-g^{*}\left(y^{*}\right)-(1-\alpha) \rho_{s}^{*}\left(\left\|x^{*}-y^{*}\right\|\right) .
\end{aligned}
$$

Letting $\alpha \rightarrow 0$ in the above inequality, we conclude that

$$
\left\langle\nabla g^{*}\left(y^{*}\right), x^{*}-y^{*}\right\rangle \leq g^{*}\left(x^{*}\right)-g^{*}\left(y^{*}\right)-\rho_{s}^{*}\left(\left\|x^{*}-y^{*}\right\|\right) \text {. }
$$

This implies that

$$
\rho_{s}^{*}\left(\left\|x^{*}-y^{*}\right\|\right) \leq D_{g^{*}}\left(x^{*}, y^{*}\right),
$$

which completes the proof.

Lemma 15 (see [35]). Let $E$ be a Banach space, let $r>0$ be a constant, and let $g: E \rightarrow \mathbb{R}$ be a continuous and convex function which is uniformly convex on bounded subsets of $E$. Then

$$
g\left(\sum_{k=0}^{\infty} \alpha_{k} x_{k}\right) \leq \sum_{k=0}^{\infty} \alpha_{k} g\left(x_{k}\right)-\alpha_{i} \alpha_{j} \rho_{r}\left(\left\|x_{i}-x_{j}\right\|\right)
$$

for all $i, j \in \mathbb{N} \cup\{0\}, x_{k} \in B_{r}, \alpha_{k} \in(0,1)$, and $k \in \mathbb{N} \cup\{0\}$ with $\sum_{k=0}^{\infty} \alpha_{k}=1$, where $\rho_{r}$ is the gauge of uniform convexity of $g$.

Lemma 16 (see [51]). Let $\left\{a_{n}\right\}_{n \in \mathbb{N}}$ be a sequence of real numbers such that there exists a subsequence $\left\{n_{i}\right\}_{i \in \mathbb{N}}$ of $\{n\}_{n \in \mathbb{N}}$ such that $a_{n_{i}}<a_{n_{i}+1}$ for all $i \in \mathbb{N}$. Then there exists a subsequence $\left\{m_{k}\right\}_{k \in \mathbb{N}} \subset \mathbb{N}$ such that $m_{k} \rightarrow \infty$ and the following properties are satisfied by all (sufficiently large) numbers $k \in \mathbb{N}$ :

$$
a_{m_{k}} \leq a_{m_{k}+1}, \quad a_{k} \leq a_{m_{k}+1} .
$$

In fact, $m_{k}=\max \left\{j \leq k: a_{j}<a_{j+1}\right\}$.

Lemma 17 (see [52-54]). Let $\left\{s_{n}\right\}_{n \in \mathbb{N}}$ be a sequence of nonnegative real numbers satisfying the inequality

$$
s_{n+1} \leq\left(1-\gamma_{n}\right) s_{n}+\gamma_{n} \delta_{n}, \quad \forall n \geq 1,
$$

where $\left\{\gamma_{n}\right\}_{n \in \mathbb{N}}$ and $\left\{\delta_{n}\right\}_{n \in \mathbb{N}}$ satisfy the following conditions:

(i) $\left\{\gamma_{n}\right\}_{n \in \mathbb{N}} \subset[0,1]$ and $\sum_{n=1}^{\infty} \gamma_{n}=\infty$, or equivalently, $\prod_{n=1}^{\infty}\left(1-\gamma_{n}\right)=0$;

(ii) $\lim \sup _{n \rightarrow \infty} \delta_{n} \leq 0$;

(ii)' $\sum_{n=1}^{\infty} \gamma_{n} \delta_{n}<\infty$. Then, $\lim _{n \rightarrow \infty} s_{n}=0$.

\section{Strong Convergence Theorems}

In this section, we prove a strong convergence theorem concerning the approximation of fixed point of Bregman weak relatively nonexpansive mappings in a reflexive Banach space. We start with the following simple lemma which has been proved in [33].

Lemma 18. Let $E$ be a reflexive Banach space and let $g: E \rightarrow$ $\mathbb{R}$ be a convex, continuous, strongly coercive, and Gâteaux differentiable function which is bounded on bounded subsets and uniformly convex on bounded subsets of E. Let $C$ be a nonempty, closed, and convex subset of E. Let $T: C \rightarrow C$ be a Bregman quasinonexpansive mapping. Then $F(T)$ is closed and convex. 
Lemma 19. Let $E$ be a reflexive Banach space and let $g: E \rightarrow$ $\mathbb{R}$ be a convex, continuous, strongly coercive, and Gâteaux differentiable function which is bounded on bounded subsets and uniformly convex on bounded subsets of E. Let $C$ be a nonempty, closed, and convex subset of $E$ and let $\left\{T_{n}\right\}_{n \in \mathbb{N}}$ be an infinite family of Bregman quasinonexpansive mappings from $C$ into itself such that $F:=\cap_{n=1}^{\infty} F\left(T_{n}\right) \neq \varnothing$. Let the mapping $T: C \rightarrow C$ be defined by

$$
T x=\lim _{n \rightarrow \infty} T_{n} x
$$

Then, $T$ is a Bregman quasinonexpansive mapping.

Proof. Let $x \in C$ and $p \in F(T)$ be fixed. Then we have that $\left\{T_{n} x\right\}_{n \in \mathbb{N}}$ is a bounded sequence in $E$. The function $g$ is bounded on bounded subsets of $E$ and, thus, $\nabla g$ is also bounded on bounded subsets of $E^{*}$ (see, e.g., [18, Proposition 1.1.11] for more details). This implies that the sequence $\left\{\nabla g\left(T_{n} x\right)\right\}_{n \in \mathbb{N}}$ is bounded in $E^{*}$. Since $\nabla g$ is uniformly normto-norm continuous on any bounded subset of $E$, we obtain

$$
\begin{aligned}
D_{g}( & p, T x) \\
= & g(p)-g(T x)-\langle x-T x, \nabla g(T x)\rangle \\
= & g(p)-g\left(\lim _{n \rightarrow \infty} T_{n} x\right) \\
& -\left\langle x-\lim _{n \rightarrow \infty} T_{n} x, \nabla g\left(\lim _{n \rightarrow \infty} T_{n} x\right)\right\rangle \\
= & \lim _{n \rightarrow \infty}\left[g(p)-g\left(T_{n} x\right)-\left\langle x-T_{n} x, \nabla g\left(T_{n} x\right)\right\rangle\right] \\
= & \lim _{n \rightarrow \infty} D_{g}\left(p, T_{n} x\right) \\
\leq & D_{g}(p, x) .
\end{aligned}
$$

Thus, $T$ is a Bregman quasinonexpansive mapping, which completes the proof.

Theorem 20. Let $E$ be a reflexive Banach space and let $g: E \rightarrow \mathbb{R}$ be a strongly coercive Bregman function which is bounded on bounded subsets and uniformly convex and uniformly smooth on bounded subsets of E. Let $C$ be a nonempty, closed and convex subset of $E$ and let $\left\{T_{n}\right\}_{n \in \mathbb{N}}$ be an infinite family of Bregman weak relatively nonexpansive mappings from $C$ into itself such that $F:=\cap_{n=1}^{\infty} F\left(T_{n}\right) \neq \varnothing$. Suppose in addition that $T_{0}=I$, where $I$ is the identity mapping on E. Let $\left\{x_{n}\right\}_{n \in \mathbb{N} \cup\{0\}}$ be a sequence generated by

$$
\begin{aligned}
x_{0} & =x \in C \text { chosen arbitrarily, } \\
C_{0} & =C, \\
y_{n} & =\nabla g^{*}\left[\alpha_{n} \nabla g\left(x_{n}\right)+\left(1-\alpha_{n}\right) \nabla g\left(T_{n} x_{n}\right)\right], \\
C_{n+1} & =\left\{z \in C_{n}: D_{g}\left(z, y_{n}\right) \leq D_{g}\left(z, x_{n}\right)\right\}, \\
x_{n+1} & =\operatorname{proj}_{C_{n+1}}^{g} x \text { and } n \in \mathbb{N} \cup\{0\},
\end{aligned}
$$

where $\nabla g$ is the gradient of $g$. Let $\left\{\alpha_{n}\right\}_{n \in \mathbb{N} \cup\{0\}}$ be a sequence in $[0,1)$ such that $\lim _{\inf }{ }_{n \rightarrow \infty} \alpha_{n}\left(1-\alpha_{n}\right)>0$.
Suppose that for any bounded subset $B$ of $C$, there exists an increasing, continuous, and convex function $h_{B}:[0,+\infty) \rightarrow$ $[0,+\infty)$ such that $h_{B}(0)=0$, and $\lim _{k, l \rightarrow \infty} \sup \left\{h_{B}\left(\| T_{k} z-\right.\right.$ $\left.\left.T_{l} z \|\right): z \in B\right\}=0$. Let $T$ be a mapping from $C$ into $E$ defined by $T x=\lim _{n \rightarrow \infty} T_{n} x$ for all $x \in C$ and suppose that $F(T)=\cap_{n=1}^{\infty} F\left(T_{n}\right)=\cap_{n=1}^{\infty} \widetilde{F}\left(T_{n}\right)=\widetilde{F}(T)$. Then $\left\{x_{n}\right\}_{n \in \mathbb{N}}$, $\left\{T_{n} x_{n}\right\}_{n \in \mathbb{N}}$, and $\left\{y_{n}\right\}_{n \in \mathbb{N}}$ converge strongly to $\operatorname{proj}_{F}^{g} x_{0}$.

Proof. We divide the proof into several steps.

Step 1. We prove that $C_{n}$ is closed and convex for each $n \in$ $\mathbb{N} \cup\{0\}$.

It is clear that $C_{0}=C$ is closed and convex. Let $C_{m}$ be closed and convex for some $m \in \mathbb{N}$. For $z \in C_{m}$, we see that

$$
D_{g}\left(z, y_{m}\right) \leq D_{g}\left(z, x_{m}\right)
$$

is equivalent to

$$
\begin{aligned}
& \left\langle z, \nabla g\left(x_{m}\right)-\nabla g\left(y_{m}\right)\right\rangle \\
& \quad \leq g\left(y_{m}\right)-g\left(x_{m}\right)+\left\langle x_{m}, \nabla g\left(x_{m}\right)\right\rangle-\left\langle y_{m}, \nabla g\left(y_{m}\right)\right\rangle .
\end{aligned}
$$

It could easily be seen that $C_{m+1}$ is closed and convex. Therefore, $C_{n}$ is closed and convex for each $n \in \mathbb{N} \cup\{0\}$.

Step 2. We claim that $F \subset C_{n}$ for all $n \in \mathbb{N} \cup\{0\}$.

It is obvious that $F \subset C_{0}=C$. Assume now that $F \subset C_{m}$ for some $m \in \mathbb{N}$. Employing Lemma 12, for any $w \in F \subset C_{m}$, we obtain

$$
\begin{aligned}
& D_{g}\left(w, y_{m}\right) \\
&=D_{g}\left(w, \nabla g^{*}\left[\alpha_{m} \nabla g\left(x_{m}\right)+\left(1-\alpha_{m}\right) \nabla g\left(T_{m} x_{m}\right)\right]\right) \\
&=V\left(w, \alpha_{m} \nabla g\left(x_{m}\right)+\left(1-\alpha_{m}\right) \nabla g\left(T_{m} x_{m}\right)\right) \\
&=\quad g(w)-\left\langle w, \alpha_{m} \nabla g\left(x_{m}\right)+\left(1-\alpha_{m} \nabla g\left(T_{m} x_{m}\right)\right)\right\rangle \\
& \quad+g^{*}\left(\alpha_{m} \nabla g\left(x_{m}\right)+\left(1-\alpha_{m}\right) \nabla g\left(T_{m} x_{m}\right)\right) \\
& \leq \alpha_{m} g(w)+\left(1-\alpha_{m}\right) g(w) \\
& \quad+\alpha_{m} g^{*}\left(\nabla g\left(x_{m}\right)\right)+\left(1-\alpha_{m}\right) g^{*}\left(\nabla g\left(T_{m} x_{m}\right)\right) \\
&=\alpha_{m} V\left(w, \nabla g\left(x_{m}\right)\right)+\left(1-\alpha_{m}\right) V\left(w, \nabla g\left(T_{m} x_{m}\right)\right) \\
&=\alpha_{m} D_{g}\left(w, x_{m}\right)+\left(1-\alpha_{m}\right) D_{g}\left(w, T_{m} x_{m}\right) \\
& \leq \alpha_{m} D_{g}\left(w, x_{m}\right)+\left(1-\alpha_{m}\right) D_{g}\left(w, x_{m}\right) \\
&= D_{g}\left(w, x_{m}\right) .
\end{aligned}
$$

This proves that $w \in C_{m+1}$ and hence $F \subset C_{n}$ for all $n \in$ $\mathbb{N} \cup\{0\}$.

Step 3. We prove that $\left\{x_{n}\right\}_{n \in \mathbb{N}},\left\{y_{n}\right\}_{n \in \mathbb{N}},\left\{z_{n}\right\}_{n \in \mathbb{N}}$, and $\left\{T_{n} x_{n}\right\}_{n \in \mathbb{N}}$ are bounded sequences in $C$. 
In view of (18), we conclude that

$$
\begin{aligned}
D_{g}\left(x_{n}, x\right) & =D_{g}\left(\operatorname{proj}_{C_{n}}^{g} x, x\right) \\
& \leq D_{g}(w, x)-D_{g}\left(w, x_{n}\right) \\
& \leq D_{g}(w, x), \quad \forall w \in F \subset C_{n}, n \in \mathbb{N} \cup\{0\} .
\end{aligned}
$$

This implies that the sequence $\left\{D_{g}\left(x_{n}, x\right)\right\}_{n \in \mathbb{N}}$ is bounded and hence there exists $M_{1}>0$ such that

$$
D_{g}\left(x_{n}, x\right) \leq M_{1}, \quad \forall n \in \mathbb{N}
$$

In view of Lemma 8(3), we conclude that the sequence $\left\{x_{n}\right\}_{n \in \mathbb{N}}$ is bounded. Since $\left\{T_{n}\right\}_{n \in \mathbb{N}}$ is an infinite family of Bregman weak relatively nonexpansive mappings from $C$ into itself, we have for any $q \in F$ that

$$
D_{g}\left(q, T_{n} x_{n}\right) \leq D_{g}\left(q, x_{n}\right), \quad \forall n \in \mathbb{N} .
$$

This, together with Definition 7 and the boundedness of $\left\{x_{n}\right\}_{n \in \mathbb{N}}$, implies that the sequence $\left\{T_{n} x_{n}\right\}_{n \in \mathbb{N}}$ is bounded.

Step 4. We show that $x_{n} \rightarrow u$ for some $u \in F$, where $u=$ $\operatorname{proj}_{F}^{g} x$.

From Step 3 it follows that $\left\{x_{n}\right\}_{n \in \mathbb{N}}$ is bounded. By the construction of $C_{n}$, we conclude that $C_{m} \subset C_{n}$ and $x_{m}=$ proj $_{C_{m}}^{g} x \in C_{m} \subset C_{n}$ for any positive integer $m \geq n$. This, together with (18), implies that

$$
\begin{aligned}
D_{g}\left(x_{m}, x_{n}\right) & =D_{g}\left(x_{m}, \operatorname{proj}_{C_{n}}^{g} x\right) \\
& \leq D_{g}\left(x_{m}, x\right)-D_{g}\left(\operatorname{proj}_{C_{n}}^{g} x, x\right) \\
& =D_{g}\left(x_{m}, x\right)-D_{g}\left(x_{n}, x\right) .
\end{aligned}
$$

In view of (16), we conclude that

$$
\begin{aligned}
D_{g}\left(x_{n}, x\right) & =D_{g}\left(\operatorname{proj}_{C_{n}}^{g} x, x\right) \\
& \leq D_{g}(w, x)-D_{g}\left(w, x_{n}\right) \\
& \leq D_{g}(w, x), \quad \forall w \in F \subset C_{n}, n \in \mathbb{N} \cup\{0\} .
\end{aligned}
$$

It follows from (68) that the sequence $\left\{D_{g}\left(x_{n}, x\right)\right\}_{n \in \mathbb{N}}$ is bounded and hence there exists $M_{2}>0$ such that

$$
D_{g}\left(x_{n}, x\right) \leq M_{2}, \quad \forall n \in \mathbb{N} .
$$

In view of (67), we conclude that

$$
\begin{aligned}
D_{g}\left(x_{n}, x\right) & \leq D_{g}\left(x_{n}, x\right)+D_{g}\left(x_{m}, x_{n}\right) \\
& \leq D_{g}\left(x_{m}, x\right), \quad \forall m \geq n .
\end{aligned}
$$

This proves that $\left\{D_{g}\left(x_{n}, x\right)\right\}_{n \in \mathbb{N}}$ is an increasing sequence in $\mathbb{R}$

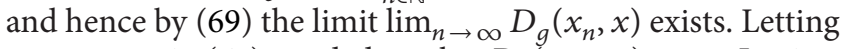
$m, n \rightarrow \infty$ in (67), we deduce that $D_{g}\left(x_{m}, x_{n}\right) \rightarrow 0$. In view of Lemma 11, we obtain that $\left\|x_{m}-x_{n}\right\| \rightarrow 0$ as $m, n \rightarrow \infty$. This means that $\left\{x_{n}\right\}_{n \in \mathbb{N}}$ is a Cauchy sequence. Since $E$ is a
Banach space and $C$ is closed and convex, we conclude that there exists $v \in C$ such that

$$
\lim _{n \rightarrow \infty}\left\|x_{n}-v\right\|=0
$$

Now, we show that $v \in F$. In view of (67), we obtain

$$
\lim _{n \rightarrow \infty} D_{g}\left(x_{n+1}, x_{n}\right)=0 \text {. }
$$

Since $x_{n+1} \in C_{n+1}$, we conclude that

$$
D_{g}\left(x_{n+1}, y_{n}\right) \leq D_{g}\left(x_{n+1}, x_{n}\right) \text {. }
$$

This, together with (72), implies that

$$
\lim _{n \rightarrow \infty} D_{g}\left(x_{n+1}, y_{n}\right)=0 \text {. }
$$

It follows from Lemma 11, (72), and (74) that

$$
\lim _{n \rightarrow \infty}\left\|x_{n+1}-x_{n}\right\|=0, \quad \lim _{n \rightarrow \infty}\left\|x_{n+1}-y_{n}\right\|=0 .
$$

In view of (71), we get

$$
\lim _{n \rightarrow \infty}\left\|y_{n}-u\right\|=0
$$

From (71) and (76), it follows that

$$
\lim _{n \rightarrow \infty}\left\|x_{n}-y_{n}\right\|=0 .
$$

Since $\nabla g$ is uniformly norm-to-norm continuous on any bounded subset of $E$, we obtain

$$
\lim _{n \rightarrow \infty}\left\|\nabla g\left(x_{n}\right)-\nabla g\left(y_{n}\right)\right\|=0 .
$$

Applying Lemma 11, we derive that

$$
\lim _{n \rightarrow \infty} D_{g}\left(y_{n}, x_{n}\right)=0 \text {. }
$$

It follows from the three point identity (see (39)) that

$$
\begin{aligned}
\left|D_{g}\left(w, x_{n}\right)-D_{g}\left(w, y_{n}\right)\right| \\
=\mid D_{g}\left(w, y_{n}\right)+D_{g}\left(y_{n}, x_{n}\right) \\
\quad+\left\langle w-y_{n}, \nabla g\left(y_{n}\right)-\nabla g\left(x_{n}\right)\right\rangle-D_{g}\left(w, y_{n}\right) \mid \\
=\left|D_{g}\left(y_{n}, x_{n}\right)-\left\langle w-y_{n}, \nabla g\left(y_{n}\right)-\nabla g\left(x_{n}\right)\right\rangle\right| \\
\leq D_{g}\left(y_{n}, x_{n}\right)+\left\|w-y_{n}\right\|\left\|\nabla g\left(y_{n}\right)-\nabla g\left(x_{n}\right)\right\| \\
\longrightarrow 0
\end{aligned}
$$

as $n \rightarrow \infty$.

The function $g$ is bounded on bounded subsets of $E$ and, thus, $\nabla g$ is also bounded on bounded subsets of $E^{*}$ (see, e.g., [18, Proposition 1.1.11] for more details). This implies that the sequences $\left\{\nabla g\left(x_{n}\right)\right\}_{n \in \mathbb{N}},\left\{\nabla g\left(y_{n}\right)\right\}_{n \in \mathbb{N}}$, and $\left\{\nabla g\left(T_{n} x_{n}\right): n \in\right.$ $\mathbb{N} \cup\{0\}\}$ are bounded in $E^{*}$.

In view of Theorem 10(3), we know that dom $g^{*}=E^{*}$ and $g^{*}$ is strongly coercive and uniformly convex on bounded subsets. Let $s_{1}=\sup \left\{\left\|\nabla g\left(x_{n}\right)\right\|,\left\|\nabla g\left(T_{n} x_{n}\right)\right\|: n \in \mathbb{N} \cup\{0\}\right\}$ 
and $\rho_{s_{1}}^{*}: E^{*} \rightarrow \mathbb{R}$ be the gauge of uniform convexity of the conjugate function $g^{*}$. We prove that for any $w \in F$,

$$
\begin{aligned}
D_{g}\left(w, y_{n}\right) \leq & D_{g}\left(w, x_{n}\right)-\alpha_{n}\left(1-\alpha_{n}\right) \rho_{s_{1}}^{*} \\
& \times\left(\left\|\nabla g\left(x_{n}\right)-\nabla g\left(T_{n} x_{n}\right)\right\|\right) .
\end{aligned}
$$

Let us show (81). For any given $w \in F(T)$, in view of the definition of the Bregman distance (see (13)), (9), Lemma 14, we obtain

$$
\begin{aligned}
& D_{g}\left(w, y_{n}\right) \\
&=D_{g}\left(w, \nabla g^{*}\left[\alpha_{n} \nabla g\left(x_{n}\right)+\left(1-\alpha_{n}\right) \nabla g\left(T_{n} x_{n}\right)\right]\right) \\
&=V\left(w, \alpha_{n} \nabla g\left(x_{n}\right)+\left(1-\alpha_{n}\right) \nabla g\left(T_{n} x_{n}\right)\right) \\
&=g(w)-\left\langle w, \alpha_{n} \nabla g\left(x_{n}\right)+\left(1-\alpha_{n}\right) \nabla g\left(T_{n} x_{n}\right)\right\rangle \\
& \quad+g^{*}\left(\alpha_{n} \nabla g\left(x_{n}\right)+\left(1-\alpha_{n}\right) \nabla g\left(T_{n} x_{n}\right)\right) \\
& \leq \alpha_{n} g(w)+\left(1-\alpha_{n}\right) g(w)-\alpha_{n}\left\langle w, \nabla g\left(x_{n}\right)\right\rangle \\
&-\left(1-\alpha_{n}\right)\left\langle w, \nabla g\left(T_{n} x_{n}\right)\right\rangle \\
&+\alpha_{n} g^{*}\left(\nabla g\left(x_{n}\right)\right)+\left(1-\alpha_{n}\right) g^{*}\left(\nabla g\left(T_{n} x_{n}\right)\right) \\
&-\alpha_{n}\left(1-\alpha_{n}\right) \rho_{s_{1}}^{*}\left(\left\|\nabla g\left(x_{n}\right)-\nabla g\left(T_{n} x_{n}\right)\right\|\right) \\
&= \alpha_{n} V\left(w, \nabla g\left(x_{n}\right)\right)+\left(1-\alpha_{n}\right) V\left(w, \nabla g\left(T_{n} x_{n}\right)\right) \\
&-\alpha_{n}\left(1-\alpha_{n}\right) \rho_{s_{1}}^{*}\left(\left\|\nabla g\left(x_{n}\right)-\nabla g\left(T_{n} x_{n}\right)\right\|\right) \\
&= \alpha_{n} D_{g}\left(w, x_{n}\right)+\left(1-\alpha_{n}\right) D_{g}\left(w, T_{n} x_{n}\right) \\
&-\alpha_{n}\left(1-\alpha_{n}\right) \rho_{s_{1}}^{*}\left(\left\|\nabla g\left(x_{n}\right)-\nabla g\left(T_{n} x_{n}\right)\right\|\right) \\
& \leq \alpha_{n} D_{g}\left(w, x_{n}\right)+\left(1-\alpha_{n}\right) D_{g}\left(w, x_{n}\right) \\
&-\alpha_{n}\left(1-\alpha_{n}\right) \rho_{s_{1}}^{*}\left(\left\|\nabla g\left(x_{n}\right)-\nabla g\left(T_{n} x_{n}\right)\right\|\right) \\
&= D_{g}\left(w, x_{n}\right)-\alpha_{n}\left(1-\alpha_{n}\right) \rho_{s_{1}}^{*}\left(\left\|\nabla g\left(x_{n}\right)-\nabla g\left(T_{n} x_{n}\right)\right\|\right)
\end{aligned}
$$

In view of (80), we obtain

$$
D_{g}\left(w, x_{n}\right)-D_{g}\left(w, y_{n}\right) \longrightarrow 0 \quad \text { as } n \longrightarrow \infty \text {. }
$$

In view of (81) and (83), we conclude that

$$
\begin{gathered}
\alpha_{n}\left(1-\alpha_{n}\right) \rho_{s_{1}}^{*}\left(\left\|\nabla g\left(x_{n}\right)-\nabla g\left(T_{n} x_{n}\right)\right\|\right) \\
\leq D_{g}\left(w, x_{n}\right)-D_{g}\left(w, y_{n}\right) \longrightarrow 0
\end{gathered}
$$

as $n \rightarrow \infty$. From the assumption $\liminf _{n \rightarrow \infty} \alpha_{n}\left(1-\alpha_{n}\right)>0$, we get

$$
\lim _{n \rightarrow \infty} \rho_{s_{1}}^{*}\left(\left\|\nabla g\left(x_{n}\right)-\nabla g\left(T_{n} x_{n}\right)\right\|\right)=0
$$

Therefore, from the property of $\rho_{s_{1}}^{*}$ we deduce that

$$
\lim _{n \rightarrow \infty}\left\|\nabla g\left(x_{n}\right)-\nabla g\left(T_{n} x_{n}\right)\right\|=0 \text {. }
$$

Since $\nabla g^{*}$ is uniformly norm-to-norm continuous on bounded subsets of $E^{*}$, we arrive at

$$
\lim _{n \rightarrow \infty}\left\|x_{n}-T_{n} x_{n}\right\|=0 .
$$

From the boundedness of $\left\{x_{n}\right\}_{n \in \mathbb{N}}$, it follows that there exists a bounded subset $B$ of $C$ such that $\left\{x_{n}\right\}_{n \in \mathbb{N}} \subset B$. Let $T x=$ $\lim _{n \rightarrow \infty} T_{n} x$ for all $x \in C$. In view of Lemma 19, $T$ is a Bregman quasinonexpansive mapping. On the other hand, we have

$$
\begin{aligned}
& \frac{1}{2}\left\|x_{n}-T x_{n}\right\| \\
& \quad \leq \frac{1}{2}\left\|x_{n}-T_{n} x_{n}\right\|+\frac{1}{2}\left\|T_{n} x_{n}-T x_{n}\right\|, \quad \forall n \in \mathbb{N} .
\end{aligned}
$$

Since $h_{B}:[0,+\infty) \rightarrow[0,+\infty)$ is an increasing, continuous, and convex function, we have

$$
\begin{aligned}
h_{B}( & \left.\frac{1}{2}\left\|x_{n}-T x_{n}\right\|\right) \\
\leq & h_{B}\left(\frac{1}{2}\left\|x_{n}-T_{n} x_{n}\right\|\right)+h_{B}\left(\frac{1}{2}\left\|T_{n} x_{n}-T x_{n}\right\|\right) \\
\leq & \frac{1}{2} h_{B}\left(\left\|x_{n}-T_{n} x_{n}\right\|\right) \\
& +\frac{1}{2} \sup \left\{h_{B}\left(\left\|T_{n} z-T z\right\|\right): z \in B\right\} .
\end{aligned}
$$

Exploiting Lemma 13 and (87), we obtain

$$
\lim _{n \rightarrow \infty} h_{B}\left(\left\|x_{n}-T x_{n}\right\|\right)=0 .
$$

By the properties of $h_{B}$, we conclude that

$$
\lim _{n \rightarrow \infty}\left\|x_{n}-T x_{n}\right\|=0 .
$$

This, together with Lemma 19 and (71), implies that $v \in$ $F(T)=\cap_{n=1}^{\infty} F\left(T_{n}\right)=F$.

Finally, we show that $v=\operatorname{proj}_{F}^{g} x$. From $x_{n}=\operatorname{proj}_{C_{n}}^{g} x$, we conclude that

$$
\left\langle z-x_{n}, \nabla g\left(x_{n}\right)-\nabla g(x)\right\rangle \geq 0, \quad \forall z \in C_{n} .
$$

Since $F \subset C_{n}$ for each $n \in \mathbb{N}$, we obtain

$$
\left\langle z-x_{n}, \nabla g\left(x_{n}\right)-\nabla g(x)\right\rangle \geq 0, \quad \forall z \in F .
$$

Letting $n \rightarrow \infty$ in (93), we deduce that

$$
\langle z-v, \nabla g(u)-\nabla g(x)\rangle \geq 0, \quad \forall z \in F .
$$

In view of (16), we have $v=\operatorname{proj}_{F}^{g} x$, which completes the proof.

Remark 21. Theorem 20 improves Theorems 1, 2, and 3 in the following aspects.

(1) For the structure of Banach spaces, we extend the duality mapping to more general case, that is, a convex, continuous, and strongly coercive Bregman function which is bounded on bounded subsets, and uniformly convex and uniformly smooth on bounded subsets. 
(2) For the mappings, we extend the mapping from a relatively nonexpansive mapping to a countable family of Bregman weak relatively nonexpansive mappings. We remove the assumption $\widehat{F}(T)=F(T)$ on the mapping $T$ and extend the result to a countable family of Bregman weak relatively nonexpansive mappings, where $\widehat{F}(T)$ is the set of asymptotic fixed points of the mapping $T$.

(3) For the algorithm, we remove the set $W_{n}$ in Theorem 1.

(4) Theorem 20 extends and improves Theorem 3.1 in [17]. We note that the proof of Theorem 3.3 (lines 2425 ) in [17] is not valid in our discussion.

(5) We note also that the main result of the paper cannot be deduced from the results of [35].

We end this section with the following simple example in order to support Theorem 20.

Example 22. Let $E,\left\{x_{n}\right\}_{n \in \mathbb{N} \cup\{0\}}$ and $g$ be as in Example 4. We define a countable family of mappings $T_{j}: E \rightarrow E$ by

$$
T_{j}(x)= \begin{cases}\frac{n}{n+1} x, & \text { if } x=x_{n} ; \\ \frac{-j}{j+1} x, & \text { if } x \neq x_{n},\end{cases}
$$

for all $j \geq 1$ and $n \geq 0$. It is clear that $F\left(T_{j}\right)=\{0\}$ for all $j \geq 1$. Choose $j \in \mathbb{N}$; then, for any $n \in \mathbb{N}$,

$$
\begin{aligned}
D_{g} & \left(0, T_{j} x_{n}\right) \\
& =g(0)-g\left(T_{j} x_{n}\right)-\left\langle 0-T_{j} x_{n}, \nabla g\left(T_{j} x_{n}\right)\right\rangle \\
& =-\frac{n^{k}}{(n+1)^{k}} g\left(x_{n}\right)+\frac{n^{k}}{(n+1)^{k}}\left\langle x_{n}, \nabla g\left(x_{n}\right)\right\rangle \\
& =\frac{n^{k}}{(n+1)^{k}}\left[-g\left(x_{n}\right)+\left\langle x_{n}, \nabla g\left(x_{n}\right)\right\rangle\right] \\
& =\frac{n^{k}}{(n+1)^{k}}\left[D_{g}\left(0, x_{n}\right)\right] \\
& \leq D_{g}\left(0, x_{n}\right) .
\end{aligned}
$$

If $x \neq x_{n}$, then we have

$$
\begin{aligned}
D_{g} & \left(0, T_{j} x\right) \\
& =g(0)-g\left(T_{j} x\right)-\left\langle 0-T_{j} x, \nabla g\left(T_{j} x\right)\right\rangle \\
& =-\frac{j^{k}}{(j+1)^{k}} g(x)-\frac{j^{k}}{(j+1)^{k}}\langle x,-\nabla g(x)\rangle \\
& =\frac{j^{k}}{(j+1)^{k}}[-g(x)-\langle-x, \nabla g(x)\rangle] \\
& \leq D_{g}(0, x) .
\end{aligned}
$$

Therefore, $T_{j}$ is a Bregman quasinonexpansive mapping. Next, we claim that $T_{j}$ is a Bregman weak relatively nonexpansive mapping. Indeed, for any sequence $\left\{z_{n}\right\}_{n \in \mathbb{N}} \subset E$ such that $z_{n} \rightarrow z_{0}$ and $\left\|z_{n}-T_{j} z_{n}\right\| \rightarrow 0$ as $n \rightarrow \infty$, there exists a sufficiently large number $N_{0} \in \mathbb{N}$ such that $z_{n} \neq x_{m}$, for any $n, m>N_{0}$. If we suppose that there exists $m \leq N$ such that $z_{n}=x_{m}$ for infinitely many $n \in \mathbb{N}$, then a subsequence $\left\{x_{n_{i}}\right\}_{i \in \mathbb{N}}$ would satisfy $z_{n_{i}}=x_{m}$, so $z_{0}=\lim _{i \rightarrow \infty} z_{n_{i}}=x_{m}$ and $z_{0}=\lim _{i \rightarrow \infty} T_{j} z_{n_{i}}=T_{j} x_{m}=(m /(m+1)) x_{m}$ which is impossible. This implies that $T_{j} z_{n}=-(j /(j+1)) z_{n}$ for all $n>$ $N_{0}$. It follows from $\left\|z_{n}-T_{j} z_{n}\right\| \rightarrow 0$ that $((2 j+1) /(j+1)) z_{n} \rightarrow$ 0 and hence $z_{n} \rightarrow z_{0}=0$. Since $z_{0} \in F\left(T_{j}\right)$, we conclude that $T_{j}$ is a Bregman weak relatively nonexpansive mapping. It is clear that $\cap_{j=1}^{\infty} \widetilde{F}\left(T_{j}\right)=\cap_{j=1}^{\infty} F\left(T_{j}\right)=\{0\}$. Thus $\left\{T_{j}\right\}_{j \in \mathbb{N}}$ is a countable family of Bregman weak relatively nonexpansive mappings. Next, we show that $\left\{T_{j}\right\}_{j \in \mathbb{N}}$ is not a countable family of Bregman relatively nonexpansive mappings. In fact, though $x_{n} \rightarrow x_{0}$ and

$$
\left\|x_{n}-T_{j} x_{n}\right\|=\left\|x_{n}-\frac{n}{n+1} x_{n}\right\|=\frac{1}{n+1}\left\|x_{n}\right\| \longrightarrow 0
$$

as $n \rightarrow \infty, x_{0} \notin F\left(T_{j}\right)$ for all $j \in \mathbb{N}$. Therefore, $\widehat{F}\left(T_{j}\right) \neq F\left(T_{j}\right)$ for all $j \in \mathbb{N}$. This implies that $\cap_{j=1}^{\infty} \widehat{F}\left(T_{j}\right) \neq \cap_{j=1}^{\infty} F\left(T_{j}\right)$. Let $T x=\lim _{j \rightarrow \infty} T_{j} x$ for all $x \in E$. It is easy to see that

$$
T(x)= \begin{cases}\frac{n}{n+1} x, & \text { if } x=x_{n} \\ -x, & \text { if } x \neq x_{n} .\end{cases}
$$

In view of Example 4, we obtain that $T$ is a Bregman weak relatively nonexpansive mapping with $F(T)=\{0\}=\widetilde{F}(T)$. Let $B$ be a bounded subset of $E$. Then there exists $r>0$ such that $B \subset B_{r}=\{z \in E:\|z\| \leq r\}$. Let $\rho_{r}$ be the gauge of uniform convexity of $g$. Then, in view of Lemma 14 , we obtain

$$
\rho_{r}(\|x-y\|) \leq D_{g}(x, y), \quad \forall x, y \in B .
$$

On the other hand, for any $k, l \in \mathbb{N}$, we have

$$
\begin{aligned}
\sup & \left\{\left\|T_{k} z-T_{l} z\right\|: z \in B\right\} \\
= & \sup \left\{\left\|\frac{-k}{k+1} z-\frac{-l}{l+1} z\right\|: z \in B\right\} \\
= & \frac{|k-l|}{(k+1)(l+1)} \sup \{\|z\|: z \in B\} .
\end{aligned}
$$

This implies that

$$
\limsup _{k, l \rightarrow \infty}\left\{\left\|T_{k} z-T_{l} z\right\|: z \in B\right\}=0 .
$$

Furthermore, we have

$$
\left.\lim _{k, l \rightarrow \infty} \sup _{k \rightarrow \infty}\left\{\left\|\rho_{k} z-T_{l} z\right\|\right): z \in B\right\}=0 .
$$

It is clear that, for any $j \in \mathbb{N}, T_{j}$ is not continuous. Finally, it is obvious that the family $\left\{T_{j}\right\}_{j \in \mathbb{N}}$ satisfies all the aspects of the hypothesis of Theorem 20. 


\section{Equilibrium Problems}

Let $C$ be a nonempty, closed, and convex of a reflexive Banach space $E$. Let $f: C \times C \rightarrow \mathbb{R}$ be a bifunction. Consider the following equilibrium problem [55]. Find $p \in C$ such that

$$
f(p, y) \geq 0, \quad \forall y \in C \text {. }
$$

For solving the equilibrium problem, let us assume that $f$ : $C \times C \rightarrow \mathbb{R}$ satisfies the following conditions:

(A1) $f(x, x)=0$ for all $x \in C$;

(A2) $f$ is monotone; that is, $f(x, y)+f(y, x) \leq 0$ for all $x, y \in C$;

(A3) for each $y \in C$, the function $x \mapsto f(x, y)$ is upper semicontinuous;

(A4) for each $x \in C$, the function $y \mapsto f(x, y)$ is convex and lower semicontinuous.

The set of solutions of problem (104) is denoted by $\operatorname{EP}(f)$.

Let $g: E \rightarrow \mathbb{R}$ be a Legendre function. The resolvent of a bifunction $f: C \times C \rightarrow \mathbb{R}[36]$ is the operator $\operatorname{Res}_{f}^{g}: E \rightarrow$ $2^{E^{*}}$, defined by

$$
\begin{gathered}
\operatorname{Res}_{f}^{g}(x)=\{z \in C: f(z, y)+\langle y-z, \nabla g(z)-\nabla g(x)\rangle \\
\geq 0 \forall y \in C\}
\end{gathered}
$$

for all $x \in E$. We also define the mapping $A_{f}: E \rightarrow 2^{E^{*}}$ in the following way:

$$
\begin{aligned}
A_{f} & (x) \\
& = \begin{cases}\left\{\xi \in E^{*}: f(x, y) \geq\langle\xi, y-x\rangle \forall y \in C\right\}, & x \in C, \\
\varnothing, & x \notin C .\end{cases}
\end{aligned}
$$

Lemma 23 (see $[36,56]$ ). Let $E$ be a reflexive Banach space and let $g: E \rightarrow \mathbb{R}$ be a convex, continuous, and strongly coercive function which is bounded on bounded subsets and uniformly convex on bounded subsets of E. Let $C$ be a nonempty, closed, and convex subset of $E$ and let $f: C \times C \rightarrow$ $\mathbb{R}$ be a bifunction satisfying (A1)-(A4) and $E P(f) \neq \varnothing$. Then, the following statements hold:

(1) $\operatorname{dom}\left(\operatorname{Res}_{f}^{g}\right)=E$;

(2) $\operatorname{Res}_{f}^{g}$ is single-valued;

(3) Res $_{f}^{g}$ is a Bregman firmly nonexpansive mapping [57]; that is, for all $x, y \in E$,

$$
\begin{aligned}
& \left\langle\operatorname{Res}_{f}^{g}(x)-\operatorname{Res}_{f}^{g}(y), \nabla g\left(\operatorname{Res}_{f}^{g}(x)\right)-\nabla g\left(\operatorname{Res}_{f}^{g}(y)\right)\right\rangle \\
& \quad \leq\left\langle\operatorname{Res}_{f}^{g}(x)-\operatorname{Res}_{f}^{g}(y), \nabla g(x)-\nabla g(y)\right\rangle ;
\end{aligned}
$$

(4) the set of fixed points of $\operatorname{Res}_{f}^{g}$ is the solution of the corresponding equilibrium problem; that is, $F\left(\operatorname{Res}_{f}^{g}\right)=$ $\mathrm{EP}(f)$;

(5) $E P(f)$ is a closed and convex subset of $C$;

(6) $D_{g}\left(q, \operatorname{Res}_{f}^{g} x\right)+D_{g}\left(\operatorname{Res}_{f}^{g} x, x\right) \leq D_{g}(q, x), \forall q \quad \in$ $F\left(\operatorname{Res}_{f}^{g}\right)$.

Lemma 24 (see [36]). Let $E$ be a reflexive Banach space and let $g: E \rightarrow \mathbb{R}$ be a convex, continuous, and strongly coercive function which is bounded on bounded subsets and uniformly convex on bounded subsets of E. Let $C$ be a nonempty, closed, and convex subset of $E$ and let $f: C \times C \rightarrow \mathbb{R}$ be a bifunction satisfying $(A 1)-(A 4)$ and $E P(f) \neq \varnothing$. Then, the following statements hold:

(1) $E P(f)=A_{f}^{-1}\left(0^{*}\right)$;

(2) $A_{f}$ is a maximal monotone operator;

(3) $\operatorname{Res}_{f}^{g}=\operatorname{Res}_{A_{f}}^{g}$.

In this section, we propose a new Halpern-type iterative scheme for finding common zeros of an infinite family of maximal monotone operators and prove the following strong convergence theorem in a Banach space.

Theorem 25. Let $E$ be a reflexive Banach space and let $g$ : $E \rightarrow \mathbb{R}$ be a strongly coercive Bregman function which is bounded on bounded subsets and uniformly convex and uniformly smooth on bounded subsets of E. For any $j \in \mathbb{N}$, let $A_{j}: E \rightarrow 2^{E^{*}}$ be a maximal monotone operator such that $Z:=\cap_{j=1}^{\infty} A_{j}^{-1}\left(0^{*}\right) \neq \varnothing$. Let $\left\{\alpha_{n}\right\}_{n \in \mathbb{N}^{N}},\left\{\beta_{n, j}\right\}_{n \in \mathbb{N}, j \in \mathbb{N} \cup\{0\}}$ be sequences in $[0,1]$ satisfying the following control conditions:

(a) $\lim _{n \rightarrow \infty} \alpha_{n}=0$;

(b) $\sum_{n=1}^{\infty} \alpha_{n}=\infty$;

(c) $\beta_{n, 0}+\sum_{j=1}^{\infty} \beta_{n, j}=1, \forall n \in \mathbb{N}$;

(d) $\liminf \operatorname{in}_{n \rightarrow \infty} \beta_{n, 0} \beta_{n, j}>0, \forall j \in \mathbb{N}$.

Let $\left\{x_{n}\right\}_{n \in \mathbb{N}}$ be a sequence generated by $u \in E, \quad x_{1} \in E$ chosen arbitrarily,

$$
\begin{aligned}
& y_{n}=\nabla g^{*}\left[\beta_{n, 0} \nabla g\left(x_{n}\right)+\sum_{j=1}^{\infty} \beta_{n, j} \nabla g\left(\operatorname{Res}_{r A_{j}}^{g}\left(x_{n}\right)\right)\right], \\
& x_{n+1}=\nabla g^{*}\left[\alpha_{n} \nabla g(u)+\left(1-\alpha_{n}\right) \nabla g\left(y_{n}\right)\right] \text { and } n \in \mathbb{N},
\end{aligned}
$$

where $\nabla g$ is the gradient of $g$ and $r>0$ is a constant. Then the sequence $\left\{x_{n}\right\}_{n \in \mathbb{N}}$ defined in (108) converges strongly to $\operatorname{proj}_{Z}^{g} u$ as $n \rightarrow \infty$.

Proof. We divide the proof into several steps. 
Let $z=\operatorname{proj}_{Z}^{g} u$. For every $j \in \mathbb{N}$, we denote by $T_{j}$ the resolvent $\operatorname{Res}_{r f_{j}}^{g}$. Therefore,

$$
y_{n}=\nabla g^{*}\left[\beta_{n, 0} \nabla g\left(x_{n}\right)+\sum_{j=1}^{\infty} \beta_{n, j} \nabla g\left(T_{j} x_{n}\right)\right] \text {. }
$$

Step 1. We prove that $\left\{x_{n}\right\}_{n \in \mathbb{N}},\left\{y_{n}\right\}_{n \in \mathbb{N}}$, and $\left\{T_{j} x_{n}: n \in \mathbb{N}, j \in\right.$ $\mathbb{N}\}$ are bounded sequences in $E$. We first show that $\left\{x_{n}\right\}_{n \in \mathbb{N}}$ is bounded. Let $p \in Z$ be fixed. In view of Lemma 12 and (108), we have

$$
\begin{aligned}
D_{g} & \left(p, y_{n}\right) \\
& =D_{g}\left(p, \nabla g^{*}\left[\beta_{n, 0} \nabla g\left(x_{n}\right)+\sum_{j=1}^{\infty} \beta_{n, j} \nabla g\left(T_{j} x_{n}\right)\right]\right) \\
& =V\left(p, \beta_{n, 0} \nabla g\left(x_{n}\right)+\sum_{j=1}^{\infty} \beta_{n, j} \nabla g\left(T_{j} x_{n}\right)\right) \\
& \leq \beta_{n, 0} V\left(p, \nabla g\left(x_{n}\right)\right)+\sum_{j=1}^{\infty} \beta_{n, j} V\left(p, \nabla g\left(T_{j} x_{n}\right)\right) \\
& =\beta_{n, 0} D_{g}\left(p, x_{n}\right)+\sum_{j=1}^{\infty} \beta_{n, j} D_{g}\left(p, T_{j} x_{n}\right) \\
& \leq \beta_{n, 0} D_{g}\left(p, x_{n}\right)+\sum_{j=1}^{\infty} \beta_{n, j} D_{g}\left(p, x_{n}\right) \\
& =D_{g}\left(p, x_{n}\right) .
\end{aligned}
$$

This implies that

$$
\begin{aligned}
D_{g} & \left(p, x_{n+1}\right) \\
& =D_{g}\left(p, \nabla g^{*}\left[\alpha_{n} \nabla g(u)+\left(1-\alpha_{n}\right) \nabla g\left(y_{n}\right)\right]\right) \\
& =V\left(p, \alpha_{n} \nabla g(u)+\left(1-\alpha_{n}\right) \nabla g\left(y_{n}\right)\right) \\
& \leq \alpha_{n} V(p, \nabla g(u))+\left(1-\alpha_{n}\right) V\left(p, \nabla g\left(y_{n}\right)\right) \\
& =\alpha_{n} D_{g}(p, u)+\left(1-\alpha_{n}\right) D_{g}\left(p, y_{n}\right) \\
& \leq \alpha_{n} D_{g}(p, u)+\left(1-\alpha_{n}\right) D_{g}\left(p, y_{n}\right) \\
& \leq \alpha_{n} D_{g}(p, u)+\left(1-\alpha_{n}\right) D_{g}\left(p, x_{n}\right) \\
& \leq \max \left\{D_{g}(p, u), D_{g}\left(p, x_{n}\right)\right\} .
\end{aligned}
$$

By induction, we obtain

$$
D_{g}\left(p, x_{n+1}\right) \leq \max \left\{D_{g}(p, u), D_{g}\left(p, x_{1}\right)\right\}
$$

for all $n \in \mathbb{N}$. It follows from (112) that the sequence $\left\{D_{g}\left(x_{n}, x\right)\right\}_{n \in \mathbb{N}}$ is bounded and hence there exists $M_{3}>0$ such that

$$
D_{g}\left(x_{n}, x\right) \leq M_{3}, \quad \forall n \in \mathbb{N}
$$

In view of Lemma 11(3), we get that the sequence $\left\{x_{n}\right\}_{n \in \mathbb{N}}$ is bounded. Since $\left\{T_{j}\right\}_{j \in \mathbb{N}}$ is an infinite family of Bregman relatively nonexpansive mappings from $E$ into itself, we conclude that

$$
D_{g}\left(p, T_{j} x_{n}\right) \leq D_{g}\left(p, x_{n}\right), \quad \forall j, n \in \mathbb{N} \text {. }
$$

This, together with Definition 7 and the boundedness of $\left\{x_{n}\right\}_{n \in \mathbb{N}}$, implies that the sequence $\left\{T_{j} x_{n}: j, n \in \mathbb{N}\right\}$ is bounded. The function $g$ is bounded on bounded subsets of $E$ and therefore $\nabla g$ is also bounded on bounded subsets of $E^{*}$ (see, e.g., [18, Proposition 1.1.11] for more details). This, together with Step 1, implies that the sequences $\left\{\nabla g\left(x_{n}\right)\right\}_{n \in \mathbb{N}}$, $\left\{\nabla g\left(y_{n}\right)\right\}_{n \in \mathbb{N}}$, and $\left\{\nabla g\left(T_{j} x_{n}\right): j, n \in \mathbb{N}\right\}$ are bounded in $E^{*}$. In view of Theorem 10(3), we obtain that dom $g^{*}=E^{*}$ and $g^{*}$ is strongly coercive and uniformly convex on bounded subsets of $E$. Let $s_{2}=\sup \left\{\left\|\nabla g\left(x_{n}\right)\right\|,\left\|\nabla g\left(T_{j} x_{n}\right)\right\|: j, n \in \mathbb{N}\right\}$ and $\rho_{s_{2}}^{*}: E^{*} \rightarrow \mathbb{R}$ be the gauge of uniform convexity of the conjugate function $g^{*}$.

Step 2. We prove that for any $j, n \in \mathbb{N}$

$$
\begin{aligned}
D_{g}\left(z, y_{n}\right) \leq & D_{g}\left(z, x_{n}\right) \\
& -\beta_{n, 0} \beta_{n, j} \rho_{s_{2}}^{*}\left(\left\|\nabla g\left(x_{n}\right)-\nabla g\left(T_{j} x_{n}\right)\right\|\right) .
\end{aligned}
$$

Let us show (115). For each $n \in \mathbb{N}$, in view of the definition of Bregman distance (see (15)), Lemmas 13, 14, 15, and (110), we obtain

$$
\begin{aligned}
& D_{g}\left(z, y_{n}\right) \\
&= g(z)-g\left(y_{n}\right)-\left\langle z-y_{n}, \nabla g\left(y_{n}\right)\right\rangle \\
&= g(z)+g^{*}\left(\nabla g\left(y_{n}\right)\right)-\left\langle y_{n}, \nabla g\left(y_{n}\right)\right\rangle \\
&-\left\langle z, \nabla g\left(y_{n}\right)\right\rangle+\left\langle y_{n}, \nabla g\left(y_{n}\right)\right\rangle \\
&= g(z)+g^{*}\left(\beta_{n, 0} \nabla g\left(x_{n}\right)+\sum_{j=1}^{\infty} \beta_{n, j} \nabla g\left(T_{j} x_{n}\right)\right) \\
&-\left\langle z, \beta_{n, j} \nabla g\left(x_{n}\right)+\sum_{j=1}^{\infty} \beta_{n, j} \nabla g\left(T_{j} x_{n}\right)\right\rangle \\
& \leq \beta_{n, 0} g(z)+\sum_{j=1}^{\infty} \beta_{n, j} g(z)+\beta_{n, 0} g^{*}\left(\nabla g\left(x_{n}\right)\right) \\
&+\sum_{j=1}^{\infty} \beta_{n, j} g^{*}\left(\nabla g\left(T_{j} x_{n}\right)\right) \\
&-\beta_{n, 0} \beta_{n, j} \rho_{s_{2}}^{*}\left(\left\|\nabla g\left(x_{n}\right)-\nabla g\left(T_{j} x_{n}\right)\right\|\right) \\
&-\beta_{n, 0}\left\langle z, \nabla g\left(x_{n}\right)\right\rangle-\sum_{j=1}^{\infty} \beta_{n, j}\left\langle z, \nabla g\left(T_{j} x_{n}\right)\right\rangle
\end{aligned}
$$




$$
\begin{aligned}
= & \beta_{n, 0}\left[g(z)+g^{*}\left(\nabla g\left(x_{n}\right)\right)-\left\langle z, \nabla g\left(x_{n}\right)\right\rangle\right] \\
& +\sum_{j=1}^{\infty} \beta_{n, j}\left[g(z)+g^{*}\left(\nabla g\left(T_{j} x_{n}\right)\right)-\left\langle z, \nabla g\left(T_{j} x_{n}\right)\right\rangle\right] \\
& -\beta_{n, 0} \beta_{n, j} \rho_{s_{2}}^{*}\left(\left\|\nabla g\left(x_{n}\right)-\nabla g\left(T_{j} x_{n}\right)\right\|\right) \\
= & \beta_{n, 0}\left[g(z)-g\left(x_{n}\right)+\left\langle x_{n}, \nabla g\left(x_{n}\right)\right\rangle-\left\langle z, \nabla g\left(x_{n}\right)\right\rangle\right] \\
& +\sum_{j=1}^{\infty} \beta_{n, j}\left[g(z)-g\left(T_{j} x_{n}\right)+\left\langle T_{j} x_{n}, \nabla g\left(T_{j} x_{n}\right)\right\rangle\right. \\
& -\beta_{n, 0} \beta_{n, j} \rho_{s_{2}}^{*}\left(\left\|\nabla g\left(x_{n}\right)-\nabla g\left(T_{j} x_{n}\right)\right\|\right) \\
= & \beta_{n, 0} D_{g}\left(z, x_{n}\right)+\sum_{j=1}^{\infty} \beta_{n, j} D_{g}\left(z, T_{j} x_{n}\right) \\
& -\beta_{n, 0} \beta_{n, j} \rho_{s_{2}}^{*}\left(\left\|\nabla g\left(x_{n}\right)-\nabla g\left(T_{j} x_{n}\right)\right\|\right) \\
\leq & \beta_{n, 0} D_{g}\left(z, x_{n}\right)+\sum_{j=1}^{\infty} \beta_{n, j} D_{g}\left(z, x_{n}\right) \\
& -\beta_{n, 0} \beta_{n, j} \rho_{s_{2}}^{*}\left(\left\|\nabla g\left(x_{n}\right)-\nabla g\left(T_{j} x_{n}\right)\right\|\right) \\
= & D_{g}\left(z, x_{n}\right)-\beta_{n, 0} \beta_{n, j} \rho_{s_{2}}^{*}\left(\left\|\nabla g\left(x_{n}\right)-\nabla g\left(T_{j} x_{n}\right)\right\|\right) .
\end{aligned}
$$

It then follows from Lemma 12 and (115) that

$$
\begin{aligned}
D_{g} & \left(z, x_{n+1}\right) \\
= & D_{g}\left(z, \nabla g^{*}\left[\alpha_{n} \nabla g(u)+\left(1-\alpha_{n}\right) \nabla g\left(y_{n}\right)\right]\right) \\
= & D_{g}\left(z, \nabla g^{*}\left[\alpha_{n} \nabla g(u)+\left(1-\alpha_{n}\right) \nabla g\left(y_{n}\right)\right]\right) \\
= & V\left(z, \alpha_{n} \nabla g(u)+\left(1-\alpha_{n}\right) \nabla g\left(y_{n}\right)\right) \\
\leq & \alpha_{n} V(z, \nabla g(u))+\left(1-\alpha_{n}\right) V\left(z, \nabla g\left(y_{n}\right)\right) \\
= & \alpha_{n} D_{g}(z, u)+\left(1-\alpha_{n}\right) D_{g}\left(z, y_{n}\right) \\
\leq & \alpha_{n} D_{g}(z, u)+\left(1-\alpha_{n}\right) D_{g}\left(z, y_{n}\right) \\
\leq & \alpha_{n} D_{g}(z, u) \\
& +\left(1-\alpha_{n}\right)\left[D_{g}\left(z, x_{n}\right)-\beta_{n, 0} \beta_{n, j} \rho_{s_{2}}^{*}\right. \\
\quad & \left.\quad \times\left\|\nabla g\left(x_{n}\right)-\nabla g\left(T_{j} x_{n}\right)\right\|\right] .
\end{aligned}
$$

Let $M_{4}:=\sup \left\{\left|D_{g}(z, u)-D_{g}\left(z, x_{n}\right)\right|+\beta_{n, 0} \beta_{n, j} \rho_{s_{2}}^{*}\left(\| \nabla g\left(x_{n}\right)-\right.\right.$ $\left.\left.\nabla g\left(T_{j} x_{n}\right) \|\right): j, n \in \mathbb{N}\right\}$. Then we get from (117) that

$$
\begin{aligned}
& \beta_{n, 0} \beta_{n, j} \rho_{s_{2}}^{*}\left(\left\|\nabla g\left(x_{n}\right)-\nabla g\left(T_{j} x_{n}\right)\right\|\right) \\
& \quad \leq D_{g}\left(z, x_{n}\right)-D_{g}\left(z, x_{n+1}\right)+\alpha_{n} M_{4}, \quad \forall j \in \mathbb{N} .
\end{aligned}
$$

In view of Lemma 12 and (115), we obtain

$$
\begin{aligned}
& D_{g}\left(z, x_{n+1}\right) \\
&=D_{g}\left(z, \nabla g^{*}\left[\alpha_{n} \nabla g(u)+\left(1-\alpha_{n}\right) \nabla g\left(y_{n}\right)\right]\right) \\
&=V\left(z, \alpha_{n} \nabla g(u)+\left(1-\alpha_{n}\right) \nabla g\left(y_{n}\right)\right) \\
& \leq V\left(z, \alpha_{n} \nabla g(u)+\left(1-\alpha_{n}\right) \nabla g\left(y_{n}\right)\right. \\
&\left.\quad-\alpha_{n}(\nabla g(u)-\nabla g(z))\right) \\
& \quad-\left\langle\nabla g^{*}\left[\alpha_{n} \nabla g(u)+\left(1-\alpha_{n}\right) \nabla g\left(y_{n}\right)\right]\right. \\
&\left.\quad-z,-\alpha_{n}(\nabla g(u)-\nabla g(z))\right\rangle \\
&=V\left(z, \alpha_{n} \nabla g(z)+\left(1-\alpha_{n}\right) \nabla g\left(y_{n}\right)\right) \\
&+\alpha_{n}\left\langle x_{n+1}-z, \nabla g(u)-\nabla g(z)\right\rangle \\
&= D_{g}\left(z, \nabla g^{*}\left[\alpha_{n} \nabla g(z)+\left(1-\alpha_{n}\right) \nabla g\left(y_{n}\right)\right]\right) \\
&+\alpha_{n}\left\langle x_{n+1}-z, \nabla g(u)-\nabla g(z)\right\rangle \\
& \leq \alpha_{n} D_{g}(z, z)+\left(1-\alpha_{n}\right) D_{g}\left(z, y_{n}\right) \\
&+\alpha_{n}\left\langle x_{n+1}-z, \nabla g(u)-\nabla g(z)\right\rangle \\
&=\left(1-\alpha_{n}\right) D_{g}\left(z, x_{n}\right) \\
&+\alpha_{n}\left\langle x_{n+1}-z, \nabla g(u)-\nabla g(z)\right\rangle .
\end{aligned}
$$

We will show that $D_{g}\left(z, x_{n}\right) \rightarrow 0$ as $n \rightarrow \infty$ by considering two possible cases on the sequence $\left\{D_{g}\left(z, x_{n}\right)\right\}_{n \in \mathbb{N}}$.

Case 1. If $\left\{D_{g}\left(z, x_{n}\right)\right\}_{n \in \mathbb{N}}$ is eventually decreasing, then there exists $n_{0} \in \mathbb{N}$ such that $\left\{D_{g}\left(z, x_{n}\right)\right\}_{n=n_{0}}^{\infty}$ is decreasing and hence $\left\{D_{g}\left(z, x_{n}\right)\right\}_{n \in \mathbb{N}}$ is convergent. Thus, we have $D_{g}\left(z, x_{n}\right)$ $D_{g}\left(z, x_{n+1}\right) \rightarrow 0$ as $n \rightarrow \infty$. This, together with condition (c) and (118), implies that

$$
\lim _{n \rightarrow \infty} \rho_{s_{2}}^{*}\left(\left\|\nabla g\left(x_{n}\right)-\nabla g\left(T_{j} x_{n}\right)\right\|\right)=0 .
$$

Therefore, from the property of $\rho_{s_{2}}^{*}$, we deduce that

$$
\lim _{n \rightarrow \infty}\left\|\nabla \mathfrak{g}\left(x_{n}\right)-\nabla g\left(T_{j} x_{n}\right)\right\|=0 \text {. }
$$

Since $\nabla g^{*}$ is uniformly norm-to-norm continuous on bounded subsets of $E^{*}$, we arrive at

$$
\lim _{n \rightarrow \infty}\left\|x_{n}-T_{j} x_{n}\right\|=0, \quad \forall j \in \mathbb{N} .
$$

Since, for any $j \in \mathbb{N}, T_{j}$ is a Bregman relatively nonexpansive mapping, there exists a subsequence $\left\{x_{n_{i}}\right\}_{i \in \mathbb{N}}$ of $\left\{x_{n}\right\}_{n \in \mathbb{N}}$ converging weakly to some $y \in Z$ such that

$$
\begin{aligned}
& \limsup _{n \rightarrow \infty}\left\langle x_{n+1}-z, \nabla g(u)-\nabla g(z)\right\rangle \\
& \quad=\lim _{i \rightarrow \infty}\left\langle x_{n_{i}+1}-z, \nabla g(u)-\nabla g(z)\right\rangle .
\end{aligned}
$$


This, together with (13), implies that

$$
\begin{array}{r}
\limsup _{n \rightarrow \infty}\left\langle x_{n+1}-z, \nabla g(u)-\nabla g(z)\right\rangle \\
\quad=\langle y-z, \nabla g(u)-\nabla g(z)\rangle \leq 0 .
\end{array}
$$

In view of Lemma 11 and (122), we obtain that

$$
\lim _{n \rightarrow \infty} D_{g}\left(T_{j} x_{n}, x_{n}\right)=0 .
$$

This implies that

$$
\begin{aligned}
D_{g}\left(T_{j} x_{n}, y_{n}\right) & \leq \beta_{n, 0} D_{g}\left(T_{j} x_{n}, x_{n}\right)+\sum_{j=1}^{\infty} \beta_{n, j} D_{g}\left(T_{j} x_{n}, T_{j} x_{n}\right) \\
& =\beta_{n, 0} D_{g}\left(T_{j} x_{n}, x_{n}\right) \longrightarrow 0
\end{aligned}
$$

as $n \rightarrow \infty$. Observe also that

$$
\begin{aligned}
D_{g}\left(y_{n}, x_{n+1}\right) & \leq \alpha_{n} D_{g}\left(y_{n}, u\right)+\left(1-\alpha_{n}\right) D_{g}\left(y_{n}, y_{n}\right) \\
& =\alpha_{n} D_{g}\left(y_{n}, u\right) \longrightarrow 0
\end{aligned}
$$

as $n \rightarrow \infty$. In view of Lemma 11 and (119), (126), and (127), we conclude that

$$
\begin{gathered}
\lim _{n \rightarrow \infty}\left\|y_{n}-T_{j} x_{n}\right\|=\lim _{n \rightarrow \infty}\left\|y_{n}-x_{n+1}\right\|=0, \\
\lim _{n \rightarrow \infty}\left\|x_{n+1}-x_{n}\right\|=\lim _{n \rightarrow \infty}\left\|y_{n}-x_{n}\right\|=0 .
\end{gathered}
$$

Moreover, from (124) and (128), we deduce that

$$
\begin{aligned}
& \limsup _{n \rightarrow \infty}\left\langle x_{n}-z, \nabla g(u)-\nabla g(z)\right\rangle \\
& \quad=\lim _{n \rightarrow \infty} \sup _{n+1}\left\langle x_{n+1}-z, \nabla g(u)-\nabla g(z)\right\rangle \leq 0 .
\end{aligned}
$$

Thus we have the desired result by Lemma 17.

Case 2. If $\left\{D_{g}\left(z, x_{n}\right)\right\}_{n \in \mathbb{N}}$ is not eventually decreasing, then there exists a subsequence $\left\{n_{i}\right\}_{i \in \mathbb{N}}$ of $\{n\}_{n \in \mathbb{N}}$ such that

$$
D_{g}\left(z, x_{n_{i}}\right)<D_{g}\left(z, x_{n_{i}+1}\right)
$$

for all $i \in \mathbb{N}$. Applying Lemma 16, we can find a nondecreasing sequence $\left\{m_{k}\right\}_{k \in \mathbb{N}} \subset \mathbb{N}$ such that $m_{k} \rightarrow \infty$,

$$
\begin{gathered}
D_{g}\left(z, x_{m_{k}}\right)<D_{g}\left(z, x_{m_{k}+1}\right), \\
D_{g}\left(z, x_{k}\right) \leq D_{g}\left(z, x_{m_{k}+1}\right)
\end{gathered}
$$

for all $k \in \mathbb{N}$. This, together with (118), implies that

$$
\begin{aligned}
& \beta_{m_{k}}\left(1-\beta_{m_{k}}\right) \rho_{s_{2}}^{*}\left(\left\|\nabla g\left(x_{m_{k}}\right)-\nabla g\left(T_{j} x_{m_{k}}\right)\right\|\right) \\
& \leq D_{g}\left(z, x_{m_{k}}\right)-D_{g}\left(z, x_{m_{k}+1}\right)+\alpha_{m_{k}} M_{4} \\
& \leq \alpha_{m_{k}} M_{4}
\end{aligned}
$$

for all $k \in \mathbb{N}$. Then, by conditions (a) and (c), we get

$$
\lim _{k \rightarrow \infty} \rho_{s_{2}}^{*}\left(\left\|\nabla g\left(x_{m_{k}}\right)-\nabla g\left(T_{j} x_{m_{k}}\right)\right\|\right)=0 .
$$

By the same argument, as in Case 1, we arrive at

$$
\begin{aligned}
\limsup _{k \rightarrow \infty}\left\langle x_{m_{k}+1}-z, \nabla g(u)-\nabla g(z)\right\rangle \\
\quad=\limsup _{k \rightarrow \infty}\left\langle x_{m_{k}}-z, \nabla g(u)-\nabla g(z)\right\rangle \leq 0 .
\end{aligned}
$$

It follows from (119) that

$$
\begin{aligned}
D_{g}\left(z, x_{m_{k}+1}\right) \leq & \left(1-\alpha_{m_{k}}\right) D_{g}\left(z, x_{m_{k}}\right) \\
& +\alpha_{m_{k}}\left\langle x_{m_{k}+1}-z, \nabla g(u)-\nabla g(z)\right\rangle .
\end{aligned}
$$

Since $D_{g}\left(z, x_{m_{k}}\right) \leq D_{g}\left(z, x_{m_{k}+1}\right)$, it follows that

$$
\begin{aligned}
\alpha_{m_{k}} D_{g}\left(z, x_{m_{k}}\right) \leq & D_{g}\left(z, x_{m_{k}}\right)-D_{g}\left(z, x_{m_{k}+1}\right) \\
& +\alpha_{m_{k}}\left\langle x_{m_{k}+1}-z, \nabla g(u)-\nabla g(z)\right\rangle \\
\leq & \alpha_{m_{k}}\left\langle x_{m_{k}+1}-z, \nabla g(u)-\nabla g(z)\right\rangle .
\end{aligned}
$$

In particular, since $\alpha_{m_{k}}>0$, we obtain

$$
D_{g}\left(z, x_{m_{k}}\right) \leq\left\langle x_{m_{k}+1}-z, \nabla g(u)-\nabla g(z)\right\rangle \text {. }
$$

In view of (135), we deduce that

$$
\lim _{k \rightarrow \infty} D_{g}\left(z, x_{m_{k}}\right)=0
$$

This, together with (136), implies that

$$
\lim _{k \rightarrow \infty} D_{g}\left(z, x_{m_{k}+1}\right)=0 \text {. }
$$

On the other hand, we have $D_{g}\left(z, x_{k}\right) \leq D_{g}\left(z, x_{m_{k}+1}\right)$ for all $k \in \mathbb{N}$ which implies that $x_{k} \rightarrow z$ as $k \rightarrow \infty$. Thus, we have $x_{n} \rightarrow z$ as $n \rightarrow \infty$.

In the following, we propose a new Halpern-type iterative scheme for finding common solutions of a system of equilibrium problems in a reflexive Banach space and obtain a strong convergence theorem.

Theorem 26. Let $E$ be a reflexive Banach space and let $g$ : $E \rightarrow \mathbb{R}$ be a strongly coercive Bregman function which is bounded on bounded subsets and uniformly convex and uniformly smooth on bounded subsets of E. Let $\left\{C_{j}\right\}_{j \in \mathbb{N}}$ be an infinite family of nonempty, closed, and convex subsets of E. For any $j \in \mathbb{N}$, let $f_{j}: C_{j} \times C_{j} \rightarrow \mathbb{R}$ be a bifunction that satisfies conditions (A1)-(A4) such that $Z:=\cap_{j=1}^{\infty} E P\left(f_{j}\right) \neq \varnothing$, where $\operatorname{EP}\left(f_{j}\right)$ is the set of solutions to the equilibrium problem (104). Let $\left\{\alpha_{n}\right\}_{n \in \mathbb{N}},\left\{\beta_{n, j}\right\}_{n \in \mathbb{N}, j \in \mathbb{N} \cup\{0\}}$ be sequences in $[0,1]$ satisfying the following control conditions:
(a) $\lim _{n \rightarrow \infty} \alpha_{n}=0$;
(b) $\sum_{n=1}^{\infty} \alpha_{n}=\infty$; 
(c) $\beta_{n, 0}+\sum_{j=1}^{\infty} \beta_{n, j}=1, \quad \forall n \in \mathbb{N}$;

(d) $\liminf \operatorname{in}_{n \rightarrow \infty} \beta_{n, 0} \beta_{n, j}>0, \forall j \in \mathbb{N}$.

Let $\left\{x_{n}\right\}_{n \in \mathbb{N}}$ be a sequence generated by

$u \in E, \quad x_{1} \in$ E chosenarbitrarily,

$y_{n}=\nabla g^{*}\left[\beta_{n, 0} \nabla g\left(x_{n}\right)+\sum_{j=1}^{\infty} \beta_{n, j} \nabla g\left(\operatorname{Res}_{r f_{j}}^{g}\left(x_{n}\right)\right)\right]$,

$x_{n+1}=\nabla g^{*}\left[\alpha_{n} \nabla g(u)+\left(1-\alpha_{n}\right) \nabla g\left(y_{n}\right)\right], \quad n \in \mathbb{N}$,

where $\nabla g$ is the gradient of $g$ and $r>0$ is a constant. Then, the sequence $\left\{x_{n}\right\}_{n \in \mathbb{N}}$ defined in (140) converges strongly to $\operatorname{proj}_{Z}^{g} u$ as $n \rightarrow \infty$.

Remark 27. (1) We propose a new type of Halpern iterative scheme for finding common zeros of an infinite family of maximal monotone operators in a reflexive Banach space. This scheme has an advantage that we do not use any projection which creates some difficulties in a practical calculation of the iterative sequence.

(2) In Theorem 25, we present a strong convergence theorem for an infinite family of maximal monotone operators with a new algorithm and new control conditions. We remove the sets $C_{n}$ and $Q_{n}$ in Theorems 5 and 6.

(3) Theorem 20 improves and extends the corresponding results of $[45,46]$ from one maximal monotone operator in Hilbert spaces to more general an infinite family of maximal monotone operators in Banach spaces.

(4) Theorem 20 improves and extends the corresponding result of [47] from two maximal monotone operators in Hilbert spaces to more general an infinite family of maximal monotone operators in Banach spaces.

(5) Theorems 25 and 26 improve and generalize Theorems 5 and 6 , respectively.

\section{Applications}

In this section, we consider the problem of finding a minimizer of a continuously Fréchet differentiable and convex function in a Banach space.

Theorem 28. Let $E$ be a reflexive Banach space and let $g$ : $E \rightarrow \mathbb{R}$ be a convex, continuous, and strongly coercive function which is bounded on bounded subsets and uniformly convex on bounded subsets of E. Let $\left\{g_{j}\right\}_{j \in \mathbb{N}}$ be an infinite family of continuously Fréchet differentiable and convex functions on $E$ such that the gradient of $g_{j}, \nabla g_{j}$ is continuous and monotone for each $j \in \mathbb{N}$. Assume that $\Omega:=\cap_{j=1}^{\infty} \arg \min _{y \in E} g_{j}(y)=$ $\left\{z \in E: g_{j}(z)=\cap_{j=1}^{\infty} \min _{y \in C} g_{j}(y)\right\} \neq \varnothing$. Let $\left\{\alpha_{n}\right\}_{n \in \mathbb{N}}$, $\left\{\beta_{n, j}\right\}_{n \in \mathbb{N}, j \in \mathbb{N} \cup\{0\}}$ be sequences in $[0,1]$ satisfying the following control conditions:
(a) $\lim _{n \rightarrow \infty} \alpha_{n}=0$;
(b) $\sum_{n=1}^{\infty} \alpha_{n}=\infty$;

(c) $\beta_{n, 0}+\sum_{j=1}^{\infty} \beta_{n, j}=1, \forall n \in \mathbb{N}$;

(d) $\liminf _{n \rightarrow \infty} \beta_{n, 0} \beta_{n, j}>0, \forall j \in \mathbb{N}$.

Let $\left\{x_{n}\right\}_{n \in \mathbb{N}}$ be a sequence generated by

$u \in E, \quad x_{1} \in C$ chosen arbitrarily,

$$
\begin{aligned}
& u_{n, j} \in C \text { suchthat }\left\langle y-u_{n, j}, \nabla g_{j}\left(u_{n, j}\right)\right\rangle \\
&+\left\langle y-u_{n, j}, \nabla g\left(u_{n, j}\right)-\nabla g\left(x_{n}\right)\right\rangle \geq 0, \quad \forall y \in C, \\
& y_{n}=\nabla g^{*}\left[\beta_{n, 0} \nabla g\left(x_{n}\right)+\sum_{j=1}^{\infty} \beta_{n, j} \nabla g\left(u_{n, j}\right)\right], \\
& x_{n+1}=\nabla g^{*}\left[\alpha_{n} \nabla g(u)+\left(1-\alpha_{n}\right) \nabla g\left(y_{n}\right)\right] \text { and } n \in \mathbb{N} .
\end{aligned}
$$

Then the sequence $\left\{x_{n}\right\}_{n \in \mathbb{N}}$ defined in (141) converges strongly to $\operatorname{proj}_{\Omega}^{g} u$ as $n \rightarrow \infty$.

\section{Conflict of Interests}

The authors declare that they have no competing interests.

\section{Acknowledgments}

The authors would like to thank the editor and the referees for sincere evaluation and constructive comments, which improved the paper considerably.

\section{References}

[1] W. Takahashi, Nonlinear Functional Analysis; Fixed Point Theory and Its Applications, Yokohama Publishers, Yokohama, Japan, 2000.

[2] W. Takahashi, Convex Analysis and Approximation of Fixed Points, Yokahama Publishers, Yokahama, Japan, 2000.

[3] K. Goebel and S. Reich, Uniform Convexity, Hyperbolic Geometry, and Nonexpansive Mappings, vol. 83 of Monographs and Textbooks in Pure and Applied Mathematics, Marcel Dekker, New York, NY, USA, 1984.

[4] W. R. Mann, "Mean value methods in iteration," Proceedings of the American Mathematical Society, vol. 4, pp. 506-510, 1953.

[5] B. Halpern, "Fixed points of nonexpanding maps," Bulletin of the American Mathematical Society, vol. 73, pp. 957-961, 1967.

[6] S. Reich, "Weak convergence theorems for nonexpansive mappings in Banach spaces," Journal of Mathematical Analysis and Applications, vol. 67, no. 2, pp. 274-276, 1979.

[7] A. Genel and J. Lindenstrauss, "An example concerning fixed points," Israel Journal of Mathematics, vol. 22, no. 1, pp. 81-86, 1975.

[8] W. Nilsrakoo and S. Saejung, "Strong convergence theorems by Halpern-Mann iterations for relatively nonexpansive mappings in Banach spaces," Applied Mathematics and Computation, vol. 217, no. 14, pp. 6577-6586, 2011.

[9] K. Nakajo and W. Takahashi, "Strong convergence theorems for nonexpansive mappings and nonexpansive semigroups," Journal of Mathematical Analysis and Applications, vol. 279, no. 2, pp. 372-379, 2003. 
[10] S. Reich, "Strong convergence theorems for resolvents of accretive operators in Banach spaces," Journal of Mathematical Analysis and Applications, vol. 75, no. 1, pp. 287-292, 1980.

[11] H. H. Bauschke, E. Matoušková, and S. Reich, "Projection and proximal point methods: convergence results and counterexamples," Nonlinear Analysis: Theory, Methods \& Applications, vol. 56, no. 5, pp. 715-738, 2004.

[12] Y. Alber, "Metric and generalized projection operators in Banach spaces: properties and applications," in Theory and Applications of Nonlinear Operators of Accretive and Monotone Type, A. Kartsatos, Ed., vol. 178 of Lecture Notes in Pure and Applied Mathematics, pp. 15-50, Marcel Dekker, New York, NY, USA, 1996.

[13] S. Reich, "A weak convergence theorem for the alternating method with Bregman distances," in Theory and Applications of Nonlinear Operators of Accretive and Monotone Type, vol. 178 of Lecture Notes in Pure and Applied Mathematics, pp. 313-318, Marcel Dekker, New York, NY, USA, 1996.

[14] S.-y. Matsushita and W. Takahashi, "A strong convergence theorem for relatively nonexpansive mappings in a Banach space," Journal of Approximation Theory, vol. 134, no. 2, pp. 257266, 2005.

[15] G. Cai and C. S. Hu, "On the strong convergence of the implicit iterative processes for a finite family of relatively weak quasinonexpansive mappings," Applied Mathematics Letters, vol. 23, no. 1, pp. 73-78, 2010.

[16] Z. Wang, Y. Su, D. Wang, and Y. Dong, "A modified Halperntype iteration algorithm for a family of hemi-relatively nonexpansive mappings and systems of equilibrium problems in Banach spaces," Journal of Computational and Applied Mathematics, vol. 235, no. 8, pp. 2364-2371, 2011.

[17] S. Plubtieng and K. Ungchittrakool, "Approximation of common fixed points for a countable family of relatively nonexpansive mappings in a Banach space and applications," Nonlinear Analysis: Theory, Methods \& Applications, vol. 72, no. 6, pp. 2896-2908, 2010.

[18] D. Butnariu and A. N. Iusem, Totally Convex Functions for Fixed Points Computation and Infinite Dimensional Optimization, vol. 40, Kluwer Academic Publishers, Dordrecht, The Netherlands, 2000.

[19] F. Kohsaka and W. Takahashi, "Proximal point algorithms with Bregman functions in Banach spaces," Journal of Nonlinear and Convex Analysis, vol. 6, no. 3, pp. 505-523, 2005.

[20] R. T. Rockafellar, "Characterization of the subdifferentials of convex functions," Pacific Journal of Mathematics, vol. 17, pp. 497-510, 1966.

[21] R. T. Rockafellar, "On the maximal monotonicity of subdifferential mappings," Pacific Journal of Mathematics, vol. 33, pp. 209216, 1970.

[22] H. H. Bauschke, J. M. Borwein, and P. L. Combettes, "Essential smoothness, essential strict convexity, and Legendre functions in Banach spaces," Communications in Contemporary Mathematics, vol. 3, no. 4, pp. 615-647, 2001.

[23] J. F. Bonnans and A. Shapiro, Perturbation Analysis of Optimization Problems, Springer Series in Operations Research, Springer, New York, NY, USA, 2000.

[24] H. H. Bauschke and J. M. Borwein, "Legendre functions and the method of random Bregman projections," Journal of Convex Analysis, vol. 4, no. 1, pp. 27-67, 1997.

[25] L. M. Bregman, "The relaxation method of finding the common point of convex sets and its application to the solution of problems in convex programming," USSR Computational Mathematics and Mathematical Physics, vol. 7, no. 3, pp. 200217, 1967.

[26] Y. Censor and A. Lent, "An iterative row-action method for interval convex programming," Journal of Optimization Theory and Applications, vol. 34, no. 3, pp. 321-353, 1981.

[27] Y. Alber and D. Butnariu, "Convergence of Bregman projection methods for solving consistent convex feasibility problems in reflexive Banach spaces," Journal of Optimization Theory and Applications, vol. 92, no. 1, pp. 33-61, 1997.

[28] E. Naraghirad, W. Takahashi, and J. C. Yao, "Generalized retraction and fixed point theorems using Bregman functions in Banach spaces," Journal of Nonlinear and Convex Analysis, vol. 13, no. 1, pp. 141-156, 2012.

[29] C. Zălinescu, Convex Analysis in General Vector Spaces, World Scientific, River Edge, NJ, USA, 2002.

[30] R. T. Rockafellar, "Monotone operators and the proximal point algorithm," SIAM Journal on Control and Optimization, vol. 14, no. 5, pp. 877-898, 1976.

[31] R. T. Rockafellar, "On the maximality of sums of nonlinear monotone operators," Transactions of the American Mathematical Society, vol. 149, pp. 75-88, 1970.

[32] H. H. Bauschke, J. M. Borwein, and P. L. Combettes, "Bregman monotone optimization algorithms," SIAM Journal on Control and Optimization, vol. 42, no. 2, pp. 596-636, 2003.

[33] S. Reich and S. Sabach, "Existence and approximation of fixed points of Bregman firmly nonexpansive mappings in reflexive Banach spaces," in Fixed-Point Algorithms for Inverse Problems in Science and Engineering, vol. 49 of Springer Optimization and Its Applications, pp. 301-316, Springer, New York, NY, USA, 2011.

[34] N. Hussain, E. Naraghirad, and A. Alotaibi, "Existence of common fixed points using Bregman nonexpansive retracts and Bregman functions in Banach spaces," Fixed Point Theory and Applications, vol. 2013, article 113, 2013.

[35] E. Naraghirad and J. C. Yao, "Bregman weak relatively nonexpansive mappings in Banach spaces," Fixed Point Theory and Applications, vol. 2013, article 141, 2013.

[36] S. Sabach, "Products of finitely many resolvents of maximal monotone mappings in reflexive Banach spaces," SIAM Journal on Optimization, vol. 21, no. 4, pp. 1289-1308, 2011.

[37] D. Butnariu, Y. Censor, and S. Reich, "Iterative averaging of entropic projections for solving stochastic convex feasibility problems," Computational Optimization and Applications, vol. 8, no. 1, pp. 21-39, 1997.

[38] D. Butnariu and E. Resmerita, "Bregman distances, totally convex functions, and a method for solving operator equations in Banach spaces," Abstract and Applied Analysis, vol. 2006, Article ID 84919, 39 pages, 2006.

[39] E. Naraghirad, "Halpern's iteration for Bregman relatively nonexpansive mappings in Banach spaces," Numerical Functional Analysis and Optimization, vol. 34, no. 10, pp. 1129-1155, 2013.

[40] Y. Su, Z. Wang, and H. K. Xu, "Strong convergence theorems for a common fixed point of two hemi-relatively nonexpansive mappings," Nonlinear Analysis: Theory, Methods \& Applications, vol. 71, no. 11, pp. 5616-5628, 2009.

[41] X. Qin, Y. J. Cho, and S. M. Kang, "Convergence theorems of common elements for equilibrium problems and fixed point problems in Banach spaces," Journal of Computational and Applied Mathematics, vol. 225, no. 1, pp. 20-30, 2009.

[42] X. Qin and Y. Su, "Strong convergence theorems for relatively nonexpansive mappings in a Banach space," Nonlinear Analysis: 
Theory, Methods \& Applications, vol. 67, no. 6, pp. 1958-1965, 2007.

[43] S. Y. Matsushita and W. Takahashi, "Weak and strong convergence theorems for relatively nonexpansive mappings in Banach spaces," Fixed Point Theory and Applications, no. 1, pp. 37-47, 2004.

[44] W. Takahashi and K. Zembayashi, "Strong and weak convergence theorems for equilibrium problems and relatively nonexpansive mappings in Banach spaces," Nonlinear Analysis: Theory, Methods \& Applications, vol. 70, no. 1, pp. 45-57, 2009.

[45] C. Tian and F. Wang, "The contraction-proximal point algorithm with square-summable errors," Fixed Point Theory and Applications, vol. 2013, article 93, 2013.

[46] F. Wang and H. Cui, "On the contraction-proximal point algorithms with multi-parameters," Journal of Global Optimization, vol. 54, no. 3, pp. 485-491, 2012.

[47] O. A. Boikanyo and G. Morosanu, "A contraction proximal point algorithm with two monotone operators," Nonlinear Analysis: Theory, Methods \& Applications, vol. 75, no. 14, pp. 5686-5692, 2012.

[48] G. Chen and M. Teboulle, "Convergence analysis of a proximallike minimization algorithm using Bregman functions," SIAM Journal on Optimization, vol. 3, no. 3, pp. 538-543, 1993.

[49] Y. Alber, "The Young-Fenchel transformation and some new characteristics of Banach spaces," in Functional Spaces, K. Jarosz, Ed., vol. 435 of Contemporary Mathematics, pp. 1-19, American Mathematical Society, Providence, RI, USA, 2007.

[50] K. Aoyama, Y. Kimura, W. Takahashi, and M. Toyoda, "Approximation of common fixed points of a countable family of nonexpansive mappings in a Banach space," Nonlinear Analysis: Theory, Methods \& Applications, vol. 67, no. 8, pp. 2350-2360, 2007.

[51] P. E. Maingé, "Strong convergence of projected subgradient methods for nonsmooth and nonstrictly convex minimization," Set-Valued Analysis, vol. 16, no. 7-8, pp. 899-912, 2008.

[52] Y. Alber, "The solution of equations and variational inequalities with maximal monotone operators," Soviet Mathematics Doklady, vol. 20, pp. 871-876, 1979.

[53] Y. Alber and A. N. Iusem, "Extension of subgradient techniques for nonsmooth optimization in Banach spaces," Set-Valued Analysis, vol. 9, no. 4, pp. 315-335, 2001.

[54] H. K. Xu, "Another control condition in an iterative method for nonexpansive mappings," Bulletin of the Australian Mathematical Society, vol. 65, no. 1, pp. 109-113, 2002.

[55] E. Blum and W. Oettli, "From optimization and variational inequalities to equilibrium problems," The Mathematics Student, vol. 63, no. 1-4, pp. 123-145, 1994.

[56] G. Kassay, S. Reich, and S. Sabach, "Iterative methods for solving systems of variational inequalities in reflexive Banach spaces," SIAM Journal on Optimization, vol. 21, no. 4, pp. 1319-1344, 2011.

[57] S. Reich and S. Sabach, "Two strong convergence theorems for Bregman strongly nonexpansive operators in reflexive Banach spaces," Nonlinear Analysis: Theory, Methods \& Applications, vol. 73, no. 1, pp. 122-135, 2010. 


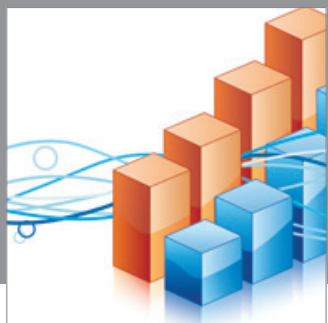

Advances in

Operations Research

mansans

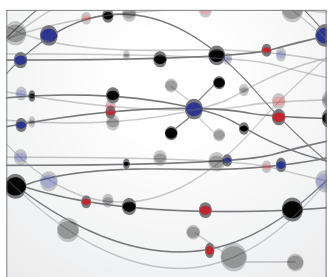

The Scientific World Journal
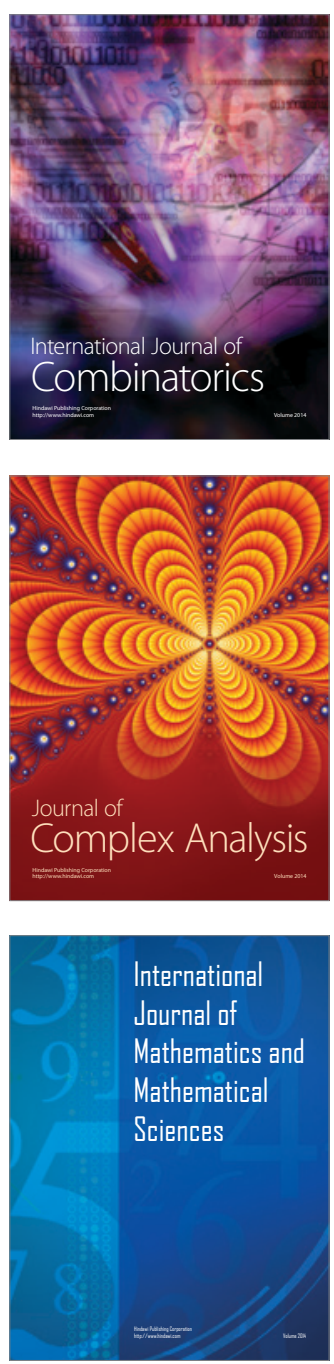
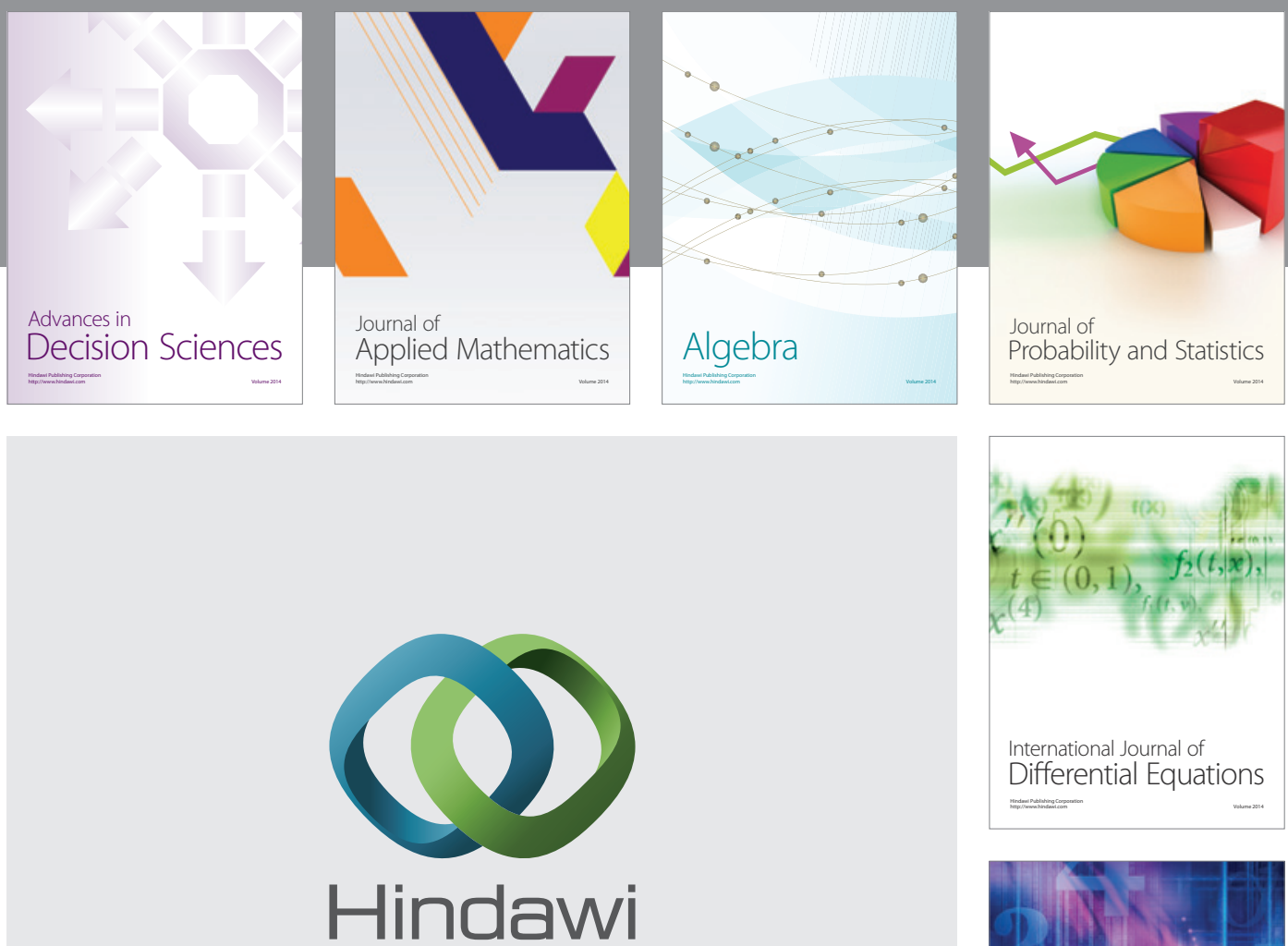

Submit your manuscripts at http://www.hindawi.com
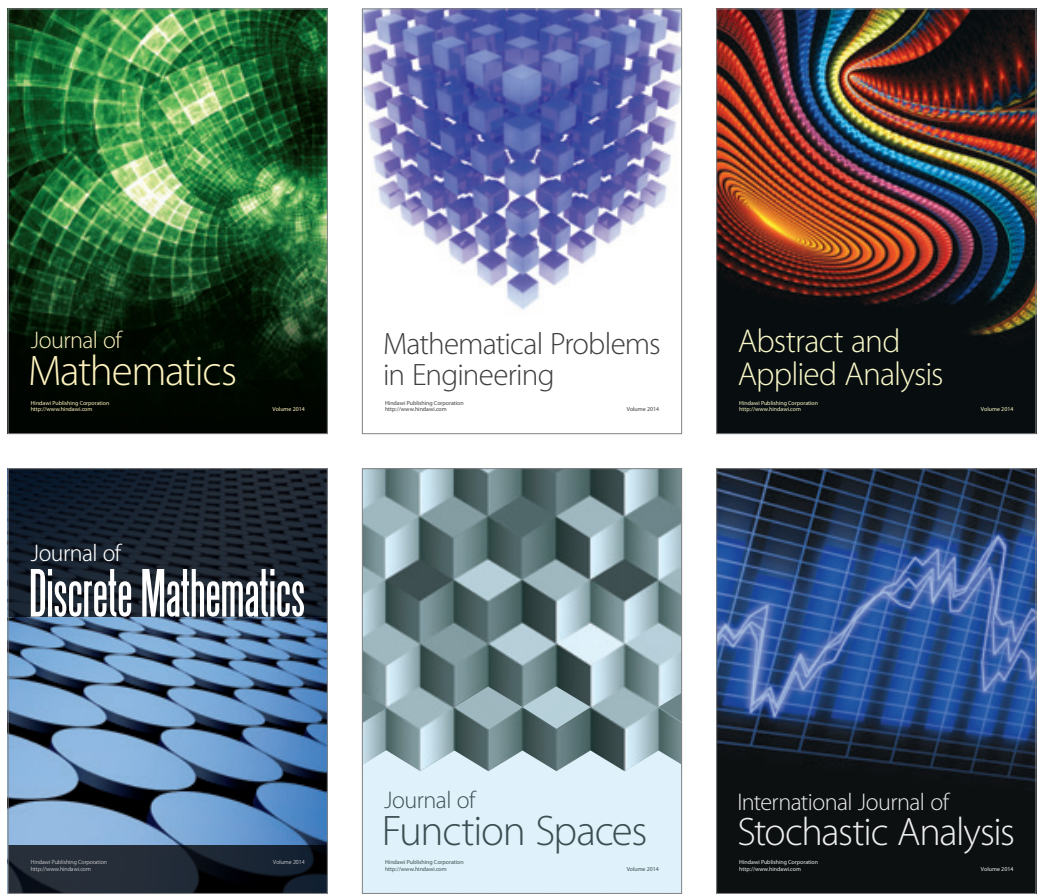

Journal of

Function Spaces

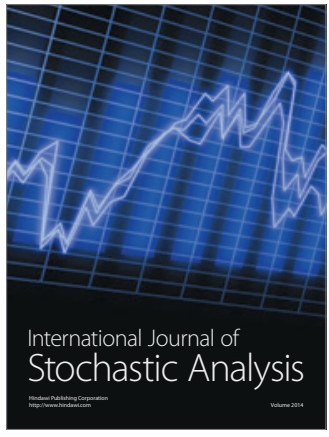

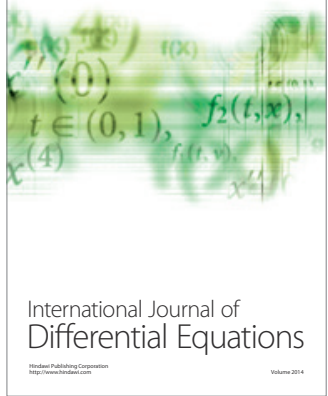
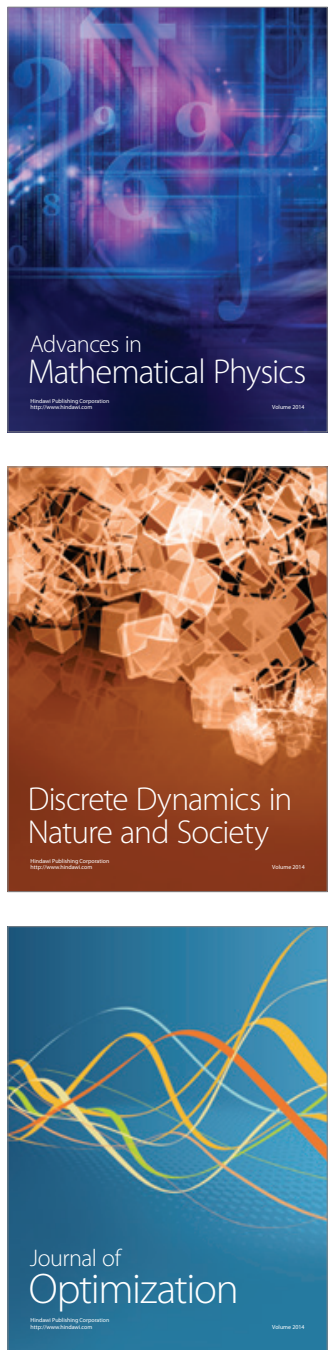